NBER WORKING PAPER SERIES

\author{
THE INCENTIVE EFFECTS OF \\ PRIVATE PENSION PLANS \\ Laurence $J$. Kotlikoff \\ David A. Wise
}

Working Paper No. 1510

\author{
NATIONAL BUREAU OF ECONOMIC RESEARCH \\ 1050 Massachusetts Avenue \\ Cambridge, MA 02138 \\ December 1984
}

The research reported here is part of the NBER's research programs in Labor Studies and Pensions. Any opinions expressed are those of the authors and not those of the National Bureau of Economic Research. 
NBER Working Paper \#1510

December 1984

The Incentive Effects of Private Pension Plans

\section{ABS TRACT}

The proportion of workers covered by pensions has increased very substantially over the past two or three decades, and in particular the number of older workers with pensions continues to increase. During the same period, and especially in the past decade, the labor force participation of older workers has declined dramatically. These two trends may well be related. This paper examines the incentive effects of private pensions. We find that the provisions of pension plans provide very substantial incentives to terminate work at the current job after the age of early retirement and even greater incentives to leave after the age of normal retirement. It is not unusual for the reduction in pension benefit accrual after these retirement ages to equal the equivalent of a 30 percent reduction in wage earnings. In addition to a potentially large impact on labor force participation of older workers, pension plan provisions are likely to have important effects on labor mobility of younger workers.

Laurence J. Kotlikoff Department of Economics Boston University Boston, MA 02115
David A. Wise J.F.K. School of Government Harvard University 79 Boylston Street Cambridge, MA 02138 
THE INCENTIVE EFFECTS OF PRIVATE PENSION PLANS

by

Laurence J. Kotlikoff and David A. Wisel

The proportion of workers covered by pensions has increased very substantially over the past two or three decades, and in particular the number of older workers with pensions continues to increase. During the same period, and especially in the past decade, the labor force participation of older workers has declined dramatically. The juxtaposition of these two trends suggests the possibility that they may be related. In this paper, we examine the stipulations of private pension plans with a view to analyzing the incentive effects created by their provisions. We find that the provisions of pension plans provide very substantial incentives to terminate work at the current job after the age of early retirement and even greater incentives to leave after the age of normal retirement. While analysis of the plan provisions suggests a potentially large effect of pension plans on labor force participation, the evidence does not directly demonstrate that pension related work incentives did indeed cause workers to leave the labor force earlier. Such conclusions must rely on the association of individual retirement decisions with the provisions of individual pension plans - an analysis that must await data as yet held from public use. Nonetheless, examination of the structure of pension plans suggests the likelihood of a very sizeable effect of plan provisions on labor force par- 
ticipation. The analysis of plan provisions also allows inferences about the cost in pension benefits of job change. In addition, the examination of plan provisions allows consideration of the differential cost of pension plans for men versus women. The wide diversity of plans and the corresponding wide diversity of the pension related work incentives is a major theme of the paper. In an earlier paper Kotlikoff and Wise (1984) emphasized the apparent inconsistency of pension accrual profiles with a spot market view of the labor market. The evidence in this paper, particularly the analysis of post normal retirement benefit accrual and supplemental benefit formulae, provides even stronger demonstration of the inconsistency. In contrast to the earlier paper which considered only a limited number of plans with earnings related benefit formulae, this paper includes the entire universe of defined benefit pension plans.

\section{Background}

\section{A. Vested Pension Benefit Accrual Profiles}

Information on the value of annual vested accrued pension benefits for workers of different ages and with different amounts of service is useful for displaying a variety of pension incentive effects. Vested pension benefit accrual at age $a, I(a)$, equals the difference between pension wealth at age $a+1, P_{w}(a+1)$, and pension wealth at age $a, P_{w}(a)$, accumulated to age $a+1$ at the nominal interest rate $r$, i.e.:

$$
I(a)=\operatorname{Pw}(a+1)-P_{w}(a)(1+r)
$$

Pension wealth at age a is defined as the expected value of vested pension benefits discounted to age a. Intuitively $P_{w}(a)$ can be thought of as the worker's pension bank account. If $I(a)$ equals zero, the worker continuing 
employment with the plan sponsor at age a has exactly the same pension wealth at, age $\mathrm{a}+I$ as an identically situated worker who terminates employment at age a. Pension accrual is thus the increment to pension wealth in excess of the return on the previously accumlated pension bank account. Throughout the paper we express pension accrual increments as a fraction of the worker's wage, $W(a)$. Specifically $R(a, t)$ denotes the ratio of $I(a)$ to $W(a)$ for a worker age a with $t$ years of service.

The appendix presents formulae for pension benefit accrual for a very simple defined benefit pension plan, emphasizing the change in the formula at ages of full or partial vesting, at early retirement age, and after normal retirement. This analysis explains why many pension age-accrual profiles show sizeable discontinuities at vesting, and early and normal retirement. It is useful here to provide a brief summary of the implications of these formulae. The discontinuities in age accrual profiles associated with vesting are fairly obvious; in the case of cliff vesting (100 percent vesting occurring at a particular age) Pw(a) in (1) equals zero prior to the age of vesting and suddenly becomes positive at the full vesting age. Hence $I(a)$ is zero prior to cliff vesting and rises to a positive value at the cliff vesting age, $a^{*}$; on the other hand, $I\left(a^{*}+1\right)$ is smaller than $I\left(a^{*}\right)$ because it represents the difference in two pension wealth numbers, rather than simply the value of one $\left(P_{w}\left(a^{*}\right)\right)$. Another discontinuity in $I(a)$ occurs, for most plans, at eerly retirement. This discontinuity occurs for plans that reduce early retirement benefits using a formla that is less than actuarially fair, and the lower the reduction the greater the decline in $I(a)$. To see this note that prior to the early retirement age $\mathrm{Pw}_{\mathrm{w}}(\mathrm{a})$ is not influenced by the early retirement reduction 
rate since workers are assumed to start collecting their vested benefits at the most lucrative date, which is almost invariably the age of early retirement; taking benefits at early retirement generally provides a larger present value of vested pension benefits accrued up to this age than opting to begin collecting these accrued benefits later. This reflects the use by pension plans of reduction rates in computing early retirement benefits that are typically lower than the actuarial rate. While $P w(a)$ and $I(a)$ are independent of the reduction rate prior to early retirement, they are both functions of the reduction factor after early retirement. The smaller the reduction factor, the closer Pw(a) will be to $\dot{\mathrm{P}}_{\mathrm{w}}(\mathrm{a}+1)$, holding other factors constant, and the smaller will be $I(a)$. This is important since the reduction factors of most plans are fairly small providing substantially less than an actuarial reduction.

A second, more fundamental reason for smaller increments after the early retirement age involves discounting. Prior to early retirement an extra dollar of benefits has a higher present value in the $P w(a+1)$ formula than in the $\mathrm{Pw}(\mathrm{a})$ formila because at age $a+1$ the worker is one year closer to receipt of these additional benefits than at age a. After the early retirement age benefits are available immediately and, ignoring the worker's shortening life span, an extra dollar of benefits at age a +1 has the same present value as an extra dollar at age a. Stated differently, after early retirement there is no special advantage from raising benefits next year over this year because, like additional benefits earned next year, additional benefits earned this year become available immediately. This lack of discounting after benefits are available raises $\mathrm{Pw}(a)$ relative to $\mathrm{Pw}(a+1)$ which implies a smaller annual pension accrual, $I(a)$, and smaller values of $R(a, t)$. 
A third factor leading to a drop in $I(a)$ at early retirement is the shorter life span during which benefits will be collected if retirement from the Olan is postponed. This factor does not enter into the calculus for I(a) prior to early retirement because, conditional on reaching early retirement, both $\mathrm{Pw}_{\mathrm{w}}(\mathrm{a}+\mathrm{I})$ and $\mathrm{Pw}(\mathrm{a})$ are based on the same potential lifespan of the worker. Each of these three factors also plays a role in the significant decline in $I(a)$ at normal retirement. Most pension plans do not increase annual benefits for workers electing to postpone receipt of pensions in years after normal retirement. This implicit zero reduction rate means a smaller value of incremental accrued benefits. The second factor involved in the drop in I(a) after early retirement is the change in discounting of $\mathrm{Pw}(a)$ relative to $\mathrm{Pw}(\mathrm{a}+$ 1). This feature continues after normal retirement as well because benefits remain immediately available. Finally, beyond the normal retirement age there is a more rapid reduction in expected lifespan and, therefore, in the expected duration of benefit receipt if the worker postpones retiring. This feature also lowers $I(a)$. (See Appendix).

While these three features help explain low and even negative values of I(a) after normal retirement, other provisions produce sharp declines in $I(a)$ at normal retirement. According to data in the 1979 BLS Level of Benefits Survey 23 percent of covered workers are enrolled in plans that do not credit service at all after normal retirement. Another 30 percent of covered workers are in plans that provide limited credit after normal retirement, and the remaining pension participants are in plans that credit all service during all years after normal retirement. Plans that provide limited credit typically credit service until the worker reaches a specified age, about age 70 on average. 
Once plans stop crediting service they either (1) commence benefit payments immediately regardless of the recipient's work status, (2) defer pension benefits until the worker actually retires, or (3) defer payment until retirement, but actuarially increase the benefit. Of the participants in the plans that provide no or limited credit, 15 percent receive immediate payments, 76 percent receive deferred payments with no actuarial increase, and the rest receive deferred payments with an actuarial increase.

\section{B. Implication of Pension Accrual Discontinuities for Viewing Lebor Market Equilibrium}

If the labor market exhibits spot market equilibrium, I(a) plus the worker's non-pension compensation at age a, W(a), equals the worker's marginal product at age a, $M(a)$ :

$$
M(a)=W(a)+I(a)
$$

Under the spot market assumption workers always receive $M(a)$ regardless of the firm or its pension plan. If $I(a)$ is smaller in one firm that another, $W(a)$ must be larger in the firm with the smaller value of $I(a)$ to insure equality of total annual compensation across firms. Since in a spot market equilibrium workers can freely move from one firm to another and firms can freely fire any worker demanding more than $M(a)$, only accrued vested benefits will have any economic value; if the value of this year's pension benefits reflected anything other than those to which the worker had legal title, either the worker or the employer would have an incentive to terminate the employment relationship. Note that the terms in (1) incorporate the spot market free mobility assumption in that workers are assumed to choose the most advantageous date to start collecting previously accumlated benefits since "retiring" for purposes of 
collecting a pension from one firm does not preclude subsequent work in another firm paying $M(a)$.

Obviously, if $W(a)$ is a smooth function of age, and $I(a)$ exhibits sharp discontinuities, $M(a)$ must exhibit sharp discontinuities at these same ages to satisfy (2). Casual empiricism suggests that $W(a)$ changes smoothly with age, or at least does not abruptly change precisely at ages when $I(a)$ exhibits sharp changes. There is also no reason to believe that $M(a)$ abruptly changes with age to satisfy (2); hence the sizeable discontinuities reported here in the $I(a)$ profile appear strikingly at odds with the spot market condition (2).

\section{Calculating Vested Benefit Accrual Profiles}

This study calculates accrual profiles for 2342 of the 2492 plans identified by the BLS as useable. 2 Throughout the paper we focus on the age profiles of the ratios of $I(a)$ to $W(a)$; $i . e$, we express the pension increments at age a as a fraction of the wage at age a. We utilize the survey's weights in presenting various average accrual profiles. The weights reflect the plan's fraction of total pension participants. To construct accrual profiles for plans which base their benefits on earnings we used a set of industry- and occupationspecific cross section age earnings profiles estimated from CPS data.

Longitudinal age earnings profiles were obtained by assuming 6 percent overall growth in wages and adding to this the wage growth by age estimated by the CPS cross section data. Kotlikoff and wise (1984) describe these estimates in detail. In the analysis here we assume that wage earnings after age 65 remain constant in nominal dollars. Our actuarial calculations employ a 9 percent nominal interest rate and use a unisex mortality table, which represents an 
average of male and female mortality probabilities. Unlike the simple formulae in the appendix, our calculations take account of the worker's survival probabilities prior to retirement as well as after retirement.

The BLS Level of Benefits Survey contains highly detailed information concerning the sampled pension plans' vesting provisions, requirements for early and normal retirement, the specifics of their normal and supplemental benefit formulae, and the crediting of service and payment of benefits for those working beyond the normal retirement age.

There is a very considerable amount of diversity in the particular provisions of private plans which generate sizeable differences in vested pension benefit accrual. Many seemingly minor features of a plan can have very important effects on benefit accrual. For example, consider a stipulation that service is credited for only 25 years in a plan that permits early retirement at 62. For a worker hired at age 30 the accrual at age 55 will decline sharply to zero and remain at zero until the early retirement age. Without this ceiling on credited service, accrual between ages 55 and 62 could be very sizeable; the weighted average ratio of pension accrual to the wage is roughly 15 percent in our sample of plans with age 62 early retirement. Other examples of very important "details" of pension provisions are age and service requirements for supplemental benefits, ceilings on the amount by which social security benefits can be used to offset pension benefits, maximum values of pension benefits, discontinuous changes by age in the rate of benefit reduction for early retirement, and maximum ages for plan participation. Each of these features, as well as numerous others not mentioned, can produce sharp discontinuities in $I$ (a) at ages other than the ages of vesting, early retirement, and normal retirement. 
Our calculations take into account each of the seemingly "minor" as well as major pension provisions included in the data.

The considerable variation in plan features within industry and occupation and, consequently, accrual profiles raises several important issues about the functioning of U.S. labor market. First, equally productive workers are likely to face very different incentives to change jobs or retire because of pension plans. Second, the heterogeneity in accrual profiles across plans suggests that equally productive workers in the same industry and occupation, but in different plans, may be receiving quite different amounts of total compensation both on an annual and on a lifetime basis. Third, equally productive workers of different sexes or ages who join the same pension plan in a firm at the same time are likely to receive very different labor remuneration, even if the quality and quantity of their labor supply is equivalent. Fourth, the complex calculations required to compute the accrual of vested benefits and, therefore, the compensation one is currently receiving, calls into question the understanding of pension compensation both on the part of employers and workers.

\section{Pension Accrual Profiles for Percent of Earnings Plans}

Percent of earnings plans are discussed in this section and flat (non earnings related) plans in the next. Variation in pension accrual profiles by early and normal retirement ages is discussed first, followed by a discussion of the wide variation among plans holding early and normal retirement ages fixed. Next we consider the effect of social security offset provisions and also examine accrual profiles by industry and by occupation. Then the effects of alternative post-normal-retirement provision are discussed. Finally there is an 
analysis of the effects on accrual profiles of early and normal retirement supplements. The cost in pension wealth of job change is discussed in section IV. Section $V$ describes the differences in the pension cost of hiring women versus men.

\section{A. The Decline in Pension Wealth Accrual at Early and Normal} Retirement Ages

Average accrual profiles for the percent of earnings plans with 10-year cliff vesting are shown in table 1 by early and normal retirement ages. Three of these average profiles corresponding to plans with the respective early and normal retirement ages $--55-55,55-65,65-65--a r e$ graphed in figure 1 . In this and subsequent figures and tables, annual accrued pension benefits are expressed as a ratio of the wage. The graph depicts the very substantial declines in the rate of pension wealth accrual at several critical ages. The first is the age of normal retirement, which equals the age of early retirement for plans with no early retirement option. Second, there is also a sharp decline in the rate of accrual at the age of early retirement, but this decline is substantially lower than the decline at the normal retirement age. 3 Third, there is a very substantial decline between ages 65 and 66 in the average accrual rate no matter what the ages of early and normal retirement.

The actual declines in average accrual rates at these critical ages indicated in table 1 are highlighted in table 2. The ages of early and normal retirement are identical in columns $1,4,6$, and 8 of the table with respective retirement ages of $55,60,62$, and 65 . At these ages the accrual rates as a percent of wages decline from .26 to $0, .27$ to $-.06, .25$ to -.13 , and .21 to -.19 respectively. Thus, at these ages the total annual compensation (wage plus 
Table 1. Welghted average eccrual rates for percent of earnings plans with 10 -year clitf vesting, by early and normal retlrement age.

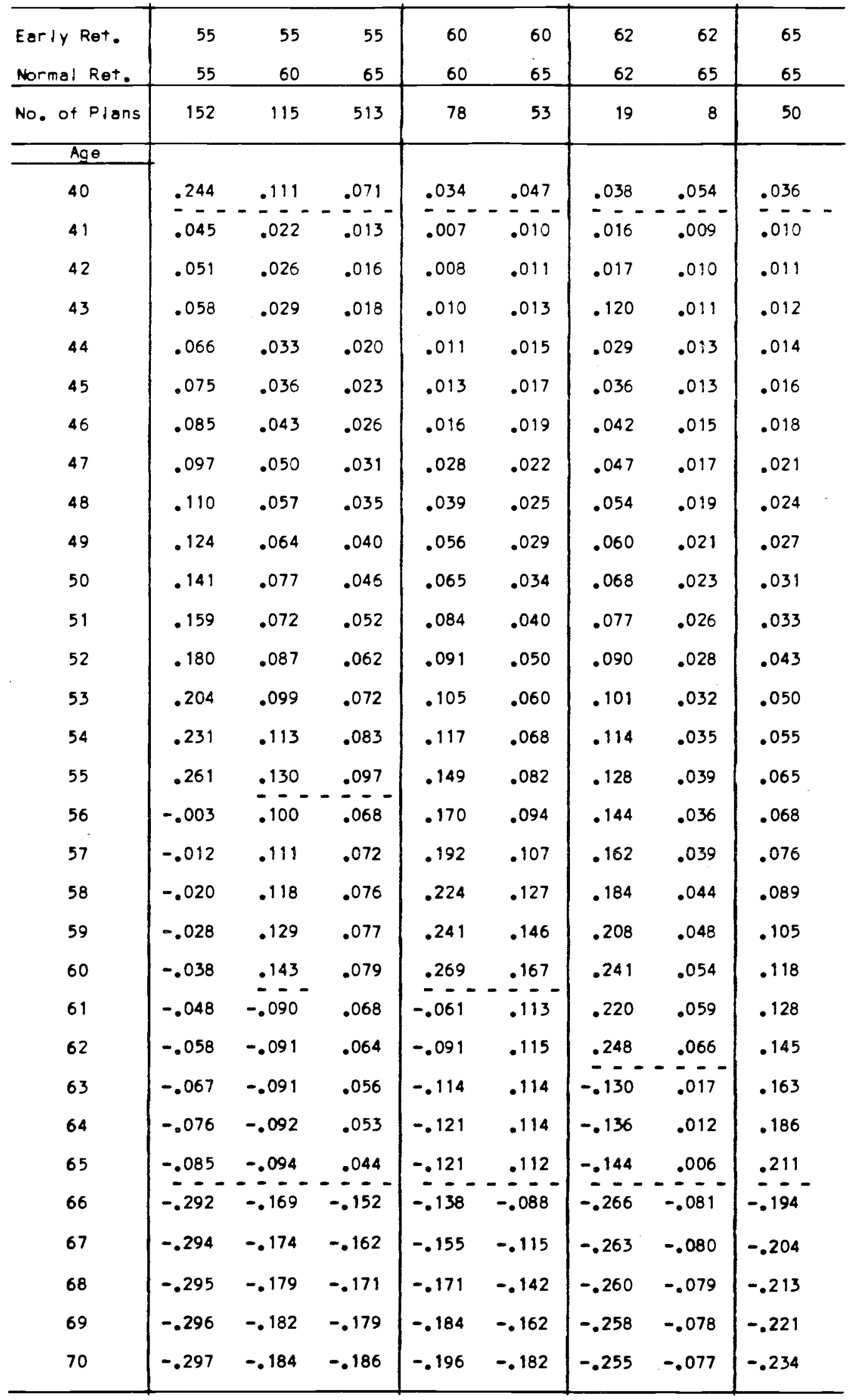

a. Plans with early or normal retirement supplements are excluded. 


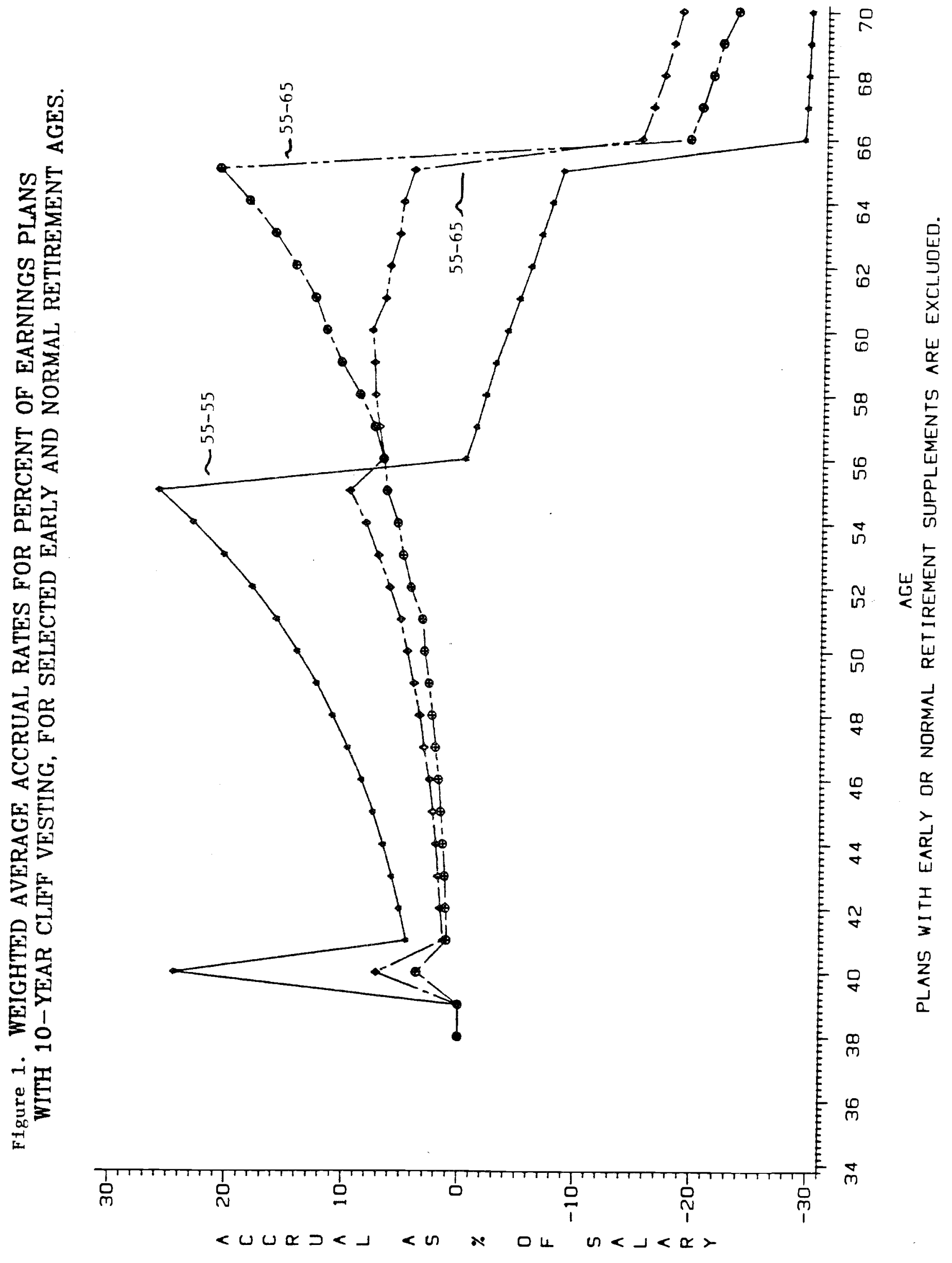


Table 2.

\begin{tabular}{|c|c|c|c|c|c|c|c|c|}
\hline \multirow{4}{*}{ Age } & \multicolumn{8}{|c|}{ Early and Normal Retirement Age } \\
\hline & (1) & (2) & (3) & (4) & $(5)$ & $(6)$ & $(7)$ & (8) \\
\hline & 55 & 55 & 55 & 60 & 60 & 62 & 62 & 65 \\
\hline & 55 & 60 & 65 & 60 & 65 & 62 & 65 & 65 \\
\hline 40 & .244 & .111 & .071 & .034 & .047 & .038 & .054 & .036 \\
\hline $\begin{array}{l}55 \\
56\end{array}$ & $\begin{array}{r}.261 \\
-.003 \\
\end{array}$ & $\begin{array}{l}.130 \\
.100\end{array}$ & $\begin{array}{l}.097 \\
.068\end{array}$ & & & & & \\
\hline $\begin{array}{l}60 \\
61\end{array}$ & & $\begin{array}{r}.143 \\
-.090 \\
\end{array}$ & & $\begin{array}{r}.269 \\
-.061 \\
\end{array}$ & $\begin{array}{l}.167 \\
.113\end{array}$ & & & \\
\hline $\begin{array}{l}62 \\
63\end{array}$ & & & & & & $\begin{array}{r}.248 \\
-.130 \\
\end{array}$ & $\begin{array}{l}.066 \\
.017\end{array}$ & \\
\hline $\begin{array}{l}65 \\
66\end{array}$ & $\begin{array}{l}-.085 \\
-.292\end{array}$ & $\begin{array}{l}-.094 \\
-.169\end{array}$ & $\begin{array}{r}.044 \\
-.152 \\
\end{array}$ & $\begin{array}{l}-.121 \\
-.138\end{array}$ & $\begin{array}{r}.112 \\
-.088 \\
\end{array}$ & $\begin{array}{l}-.144 \\
-.266\end{array}$ & $\begin{array}{r}.006 \\
-.081 \\
\end{array}$ & $\begin{array}{r}.211 \\
-.194\end{array}$ \\
\hline 70 & -.297 & -.184 & -.186 & -.196 & -.182 & -.255 & -.077 & -.234 \\
\hline $65-66$ & 20 & 8 & 19 & 2 & 20 & 12 & 8 & 40 \\
\hline
\end{tabular}


pension accrual) from working declines by 21 percent, 26 percent, 30 percent, and 33 percent respectively. Surely then the incentive to continue work with the current employer past these ages is very substantially reduced.

In instances where early and normal retirement ages do not coincide, there is also a very substantial decline in the ratio of pension accrual to the wage at the age of normal retirement. For example, among plans with early retirement at 55 and normal retirement at 60 the decline is from .14 to -.09 . There is also a decline at the age of early retirement for these plans, although it is considerably less substantial than the decline at the age of normal retirement. For example, of plans with early retirement at 55 and normal retirement at 65 the decline at 55 is from .10 to .07 , while at 65 the decline is from .04 to -.15 .

Finally, in all cases there is a substantial decline in the rate of pension accrual between ages 65 and 66 . The effective reduction in compensation ranges from 8 percent to 40 percent of the wage rate except for plans with early and normal retirement at 60 , in which case the decline is from -.12 to -.14 . Thus while the stipulations of plans vary tremendously, these plans, on average, seem to provide a substantial inducement to retirement after age 65 , no matter what the inducement before this age.

The figure and the table also show a large variation in average pension accrual at 40 , the age of cliff vesting. It is highest, on average, for plans with early and normal retirement at 55 and lowest, on average, for plans with early and normal retirement at 65. As mentioned, because the early retirement reduction is typically less than actuarially fair, pension wealth is generally greatest if benefits are taken at the age of early retirement. Thus the accrued 
wealth at the age of vesting is usually calculated by discounting benefits from the age of early retirement, assuming that the worker could begin to collect benefits at that age. Figure 1, for example, shows a vesting spike of almost 25 percent of earnings for 55-55 plans, 7 percent of earnings for $55-65$ plans, and about 4 percent of earnings for $65-65$ plans.

In summary, it seems apparent that continuation in the labor force after the age of normal retirement and sometimes early retirement as well typically involves a substantial reduction in compensation because of the very large declines in the rate of pension wealth accrual. After the age of 65 , there is typically a substantial loss in pension accrual, no matter what the ages of early and normal retirement. And, the sharp changes in average pension accrual at particular ages provides rather strong prima facia evidence against annual spot market clearing; neither wages nor marginal products appear to adjust at these critical ages to meet the spot market equilibrium condition written in (1).

\section{B. Variation Among Plans}

Even among plans with the same early and normal retirement ages there is wide variation in accrual rates at each age, particularly after the age of early retirement. To demonstrate this fact, average accrual rates for the 513 plans of table 1 with early retirement at 55 and normal retirement at 65 , together with median, maximum, minimum and upper and lower 5 percentile levels, are shown in table 3 . The lower 5 percentile points for any age group for example is that accrual rate such that 5 percent of plans have accruals below that level. The upper 5 percentile point is defined analogously. Consider the accrual ratio at vesting. While the average vesting ratio for this smaple is 
Table 3. Dispersion of accrual ratios for table 1 plans with age 55 early retirement and age 65 normal retirement.

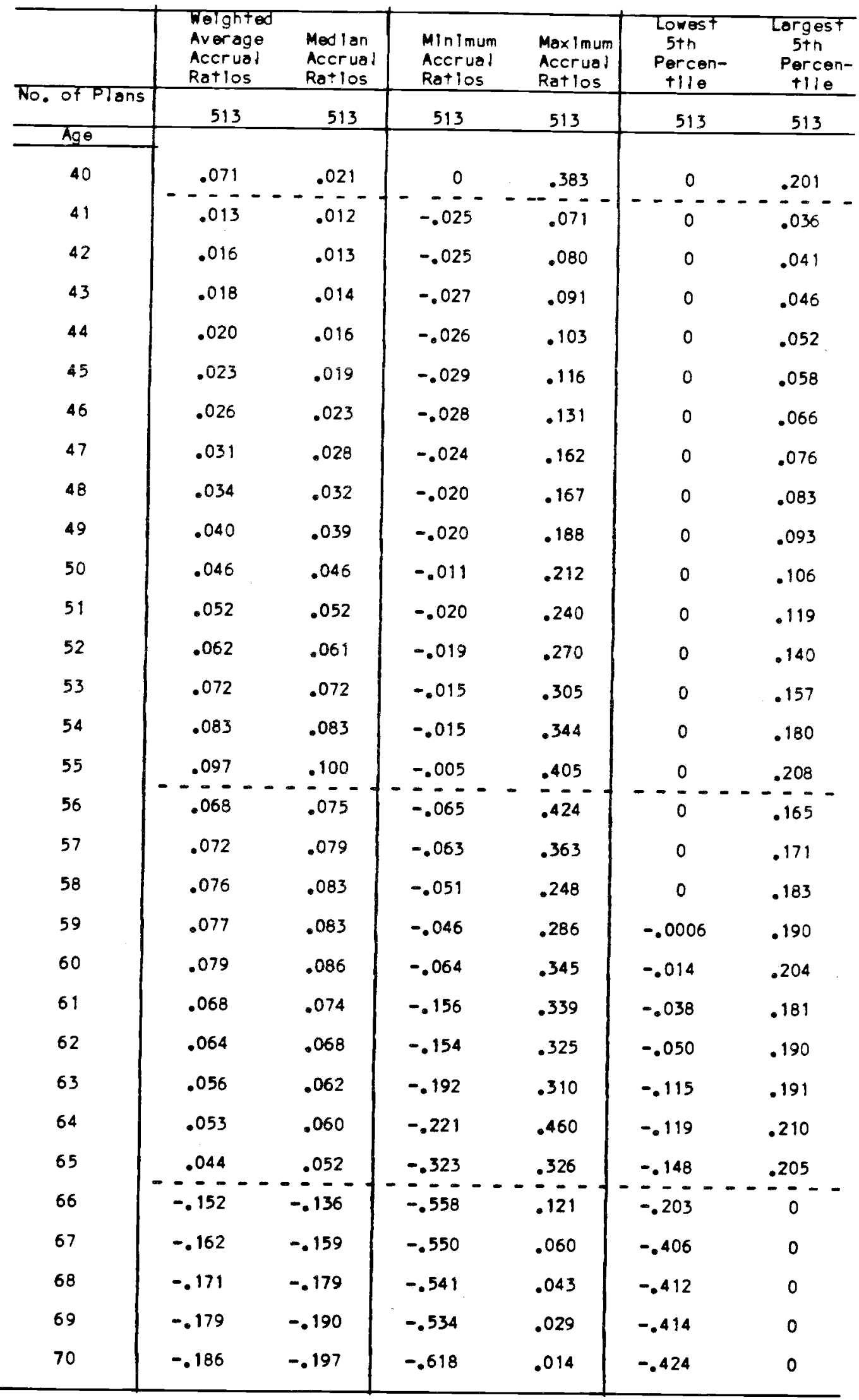


.071 , the median is .021 , the maximum is .383 , and the minimum is 0 . The ratio at the lowest 5 th percentile is 0 , while it ir .201 for the largest 5 th percentile. A similarly large dispersion in annual accrual ratios is indicated for each of the ages 40 through 70 . Weighted average accrual rates together with upper and lower 5 percentile levels are graphed in figure 2. While the average accrual rates between ages 55 and 65 are positive, for many plans the rates by 65 are very negative. Thus it is important to base judgements about the labor force participation incentive effects of pension plans not simply on the basis of average accrual rates.

Additional evidence of the variability of pension accrued profiles is obtained by comparing profiles of particular plans. Figure 3 plots the accrual profiles of four of the sample's 30 largest plans. Plan l exhibits a 29 percent vesting spike, a reduction of 30 percentage points in the accrual ratio at age 55 and a further major reduction at age 65 from -.063 to -.351 . In contrast the vesting spike is only 4 percent for plan 2 in the figure. This plan also exhibits no major reduction in the accrual ratio at early retirement anc only a minor reduction at normal retirement. Plan 3's vesting spike is mich less than that of plan 1, but the drop off of the accrual ratio at age 55 is very uch larger than that in plan 1. This plan also exhibits extremely sharp changes in accrual ratios at ages 60 , and 63 . Plan 4 exhibits even greater discontinuities in the accrual profile. Thus the plans' incentive effects on labor force participation also vary widely.

\section{The Effect of Social Security Offsets}

As described above, a substantial number of plans have social security offset provisions, under which pension benefits are reduced by an amount 


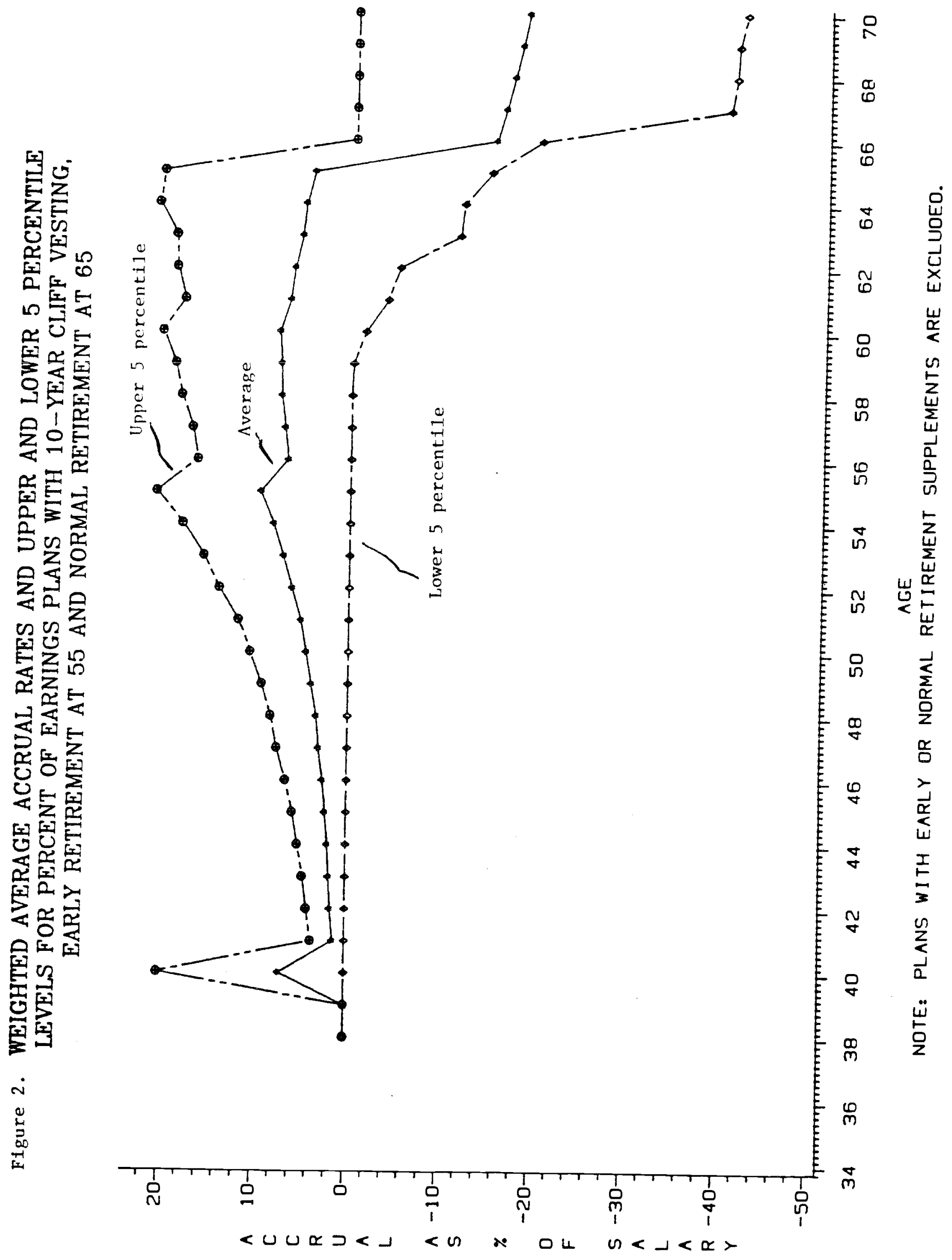


年

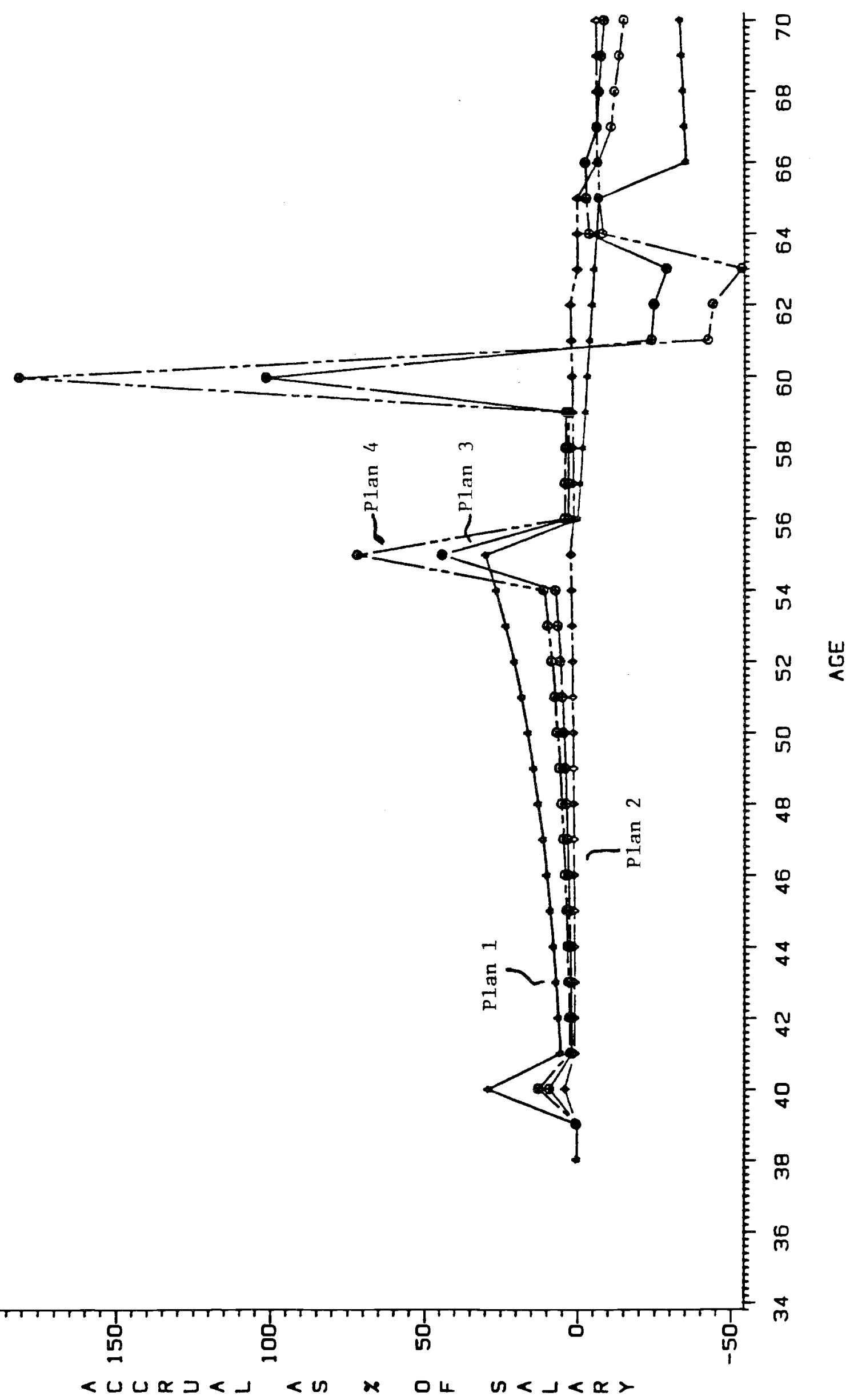


depending upon the recipients' social security benefits. The offset provisions vary widely among plans. In some instances the offset is enough to completely eliminate payment of pension benefits from the private pension plan. Private pension benefit payments are typically substantially lower with than without the offset provision. Accrual rates for percent of earning plans with 10-year cliff vesting and early retirement at 55 are shown in table 4 for selected normal retirement ages, with and without social security offset provisions. The average profiles for offset and non-offset plans with early retirement at 55 and normal retirement at 62 are graphed in figure 4. A noticeable difference between the two groups of plans is the relatively large spike at vesting for plans without the offset compared with the low rate of accrual at vesting for plans with the social security offset. In addition, the accrual ratio at 55 is larger for plans without the offset than for plans with it, and the drop in the rate of accrual is substantially larger for plans without than for plans with the offset. The accrual ratio for plans without an offset is .21 at 55 and drops by almost 60 percent to .09 at 56. In contrast, the accrual rate for plans with an offset is about 16 percent at 55 and drops by only about 26 percent to .12 at age 56. Both groups of plans show negative accrual rates after the age of normal retirement, 62 , and both groups of plans show mich larger negative accrual rates after 65 . Table 4 indicates that the relative accrual rates of the two groups for plans with different normal retirement ages are similar to those shown in the figure.

The table also shows that pension accrual at the age of vesting is rather substantial for plans without a social security offset even among plans with normal retirement at 65 . The average accrual rate at vesting for all plans 
Table 4. Welghted overage accrual rates for percent of earnings plans

with 10-year cllift vesting and early retlirement at age 55, by normal retirement age and soclal security of fset.

\begin{tabular}{|c|c|c|c|c|c|c|}
\hline \multirow{2}{*}{$\begin{array}{l}\text { Normal Ret. } \\
\text { oftset } \\
\text { No. of Plans } \\
\text { Age }\end{array}$} & \multicolumn{2}{|c|}{$\begin{array}{cc}w / 0 \text { oftset } & 55 \\
135 & 17\end{array}$} & \multicolumn{2}{|c|}{ 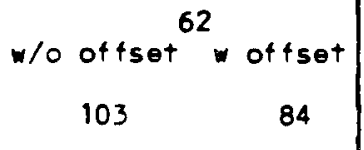 } & \multicolumn{2}{|c|}{$\begin{array}{cc}w / 0 \text { offset } \\
254 & 259\end{array}$} \\
\hline & \multirow[b]{2}{*}{-.260} & \multirow[b]{2}{*}{$\begin{array}{r}.073 \\
.005\end{array}$} & & & \multirow[b]{2}{*}{.121} & \multirow[b]{2}{*}{$-\frac{.016}{.004}$} \\
\hline 41 & & & -.175 & $\begin{array}{l}.030 \\
-.010\end{array}$ & & \\
\hline 42 & .055 & .008 & .039 & .014 & .026 & .005 \\
\hline 43 & .062 & .010 & .044 & .017 & .029 & .006 \\
\hline 44 & .071 & .013 & .049 & .020 & .033 & .007 \\
\hline 45 & .060 & .017 & .064 & .024 & .037 & .009 \\
\hline 46 & .090 & .030 & .064 & .027 & .041 & .011 \\
\hline 47 & .102 & .039 & .074 & .034 & .078 & .013 \\
\hline 48 & .115 & .047 & .086 & .040 & .052 & .016 \\
\hline 49 & .130 & .061 & .100 & .049 & .058 & .019 \\
\hline 50 & .147 & .074 & .112 & .066 & .065 & .025 \\
\hline 51 & .166 & .089 & .127 & .079 & .072 & .029 \\
\hline 52 & .187 & .108 & .143 & .096 & .081 & .041 \\
\hline 53 & .211 & .127 & .165 & .112 & .091 & .051 \\
\hline 54 & .238 & .146 & .185 & .132 & .102 & .062 \\
\hline 55 & .269 & .175 & .213 & .155 & .116 & .076 \\
\hline 56 & -.008 & .042 & .090 & .115 & .078 & .058 \\
\hline 57 & -.016 & .036 & .092 & .120 & .077 & .065 \\
\hline 58 & -.025 & .040 & .103 & .135 & .076 & .076 \\
\hline 59 & -.034 & .034 & .096 & .140 & .073 & .082 \\
\hline 60 & -.043 & .025 & .087 & .143 & .069 & .091 \\
\hline 61 & -.052 & -.004 & .090 & .109 & .071 & .066 \\
\hline 62 & -.062 & -.012 & .087 & .110 & .061 & .068 \\
\hline 63 & -.071 & -.024 & -.075 & -.066 & .047 & .066 \\
\hline 64 & -.081 & -.026 & -.086 & -.069 & .040 & .067 \\
\hline 65 & $\begin{array}{r}-.090 \\
-.-.-\end{array}$ & $=.032$ & $=.098$ & -.074 & .025 & .066 \\
\hline 66 & -.309 & -.109 & -.224 & -.154 & -.203 & -.097 \\
\hline 67 & -.309 & -.132 & -.248 & -.170 & -.212 & -.108 \\
\hline 68 & -.308 & -.153 & -.270 & -.184 & -.219 & -.119 \\
\hline 69 & -.307 & -.172 & -.280 & -.196 & -.227 & -.128 \\
\hline 70 & -.307 & -.191 & -.290 & -.204 & -.233 & -.136 \\
\hline
\end{tabular}

a. Plans with early or normal retirement supplements are axcluded. 

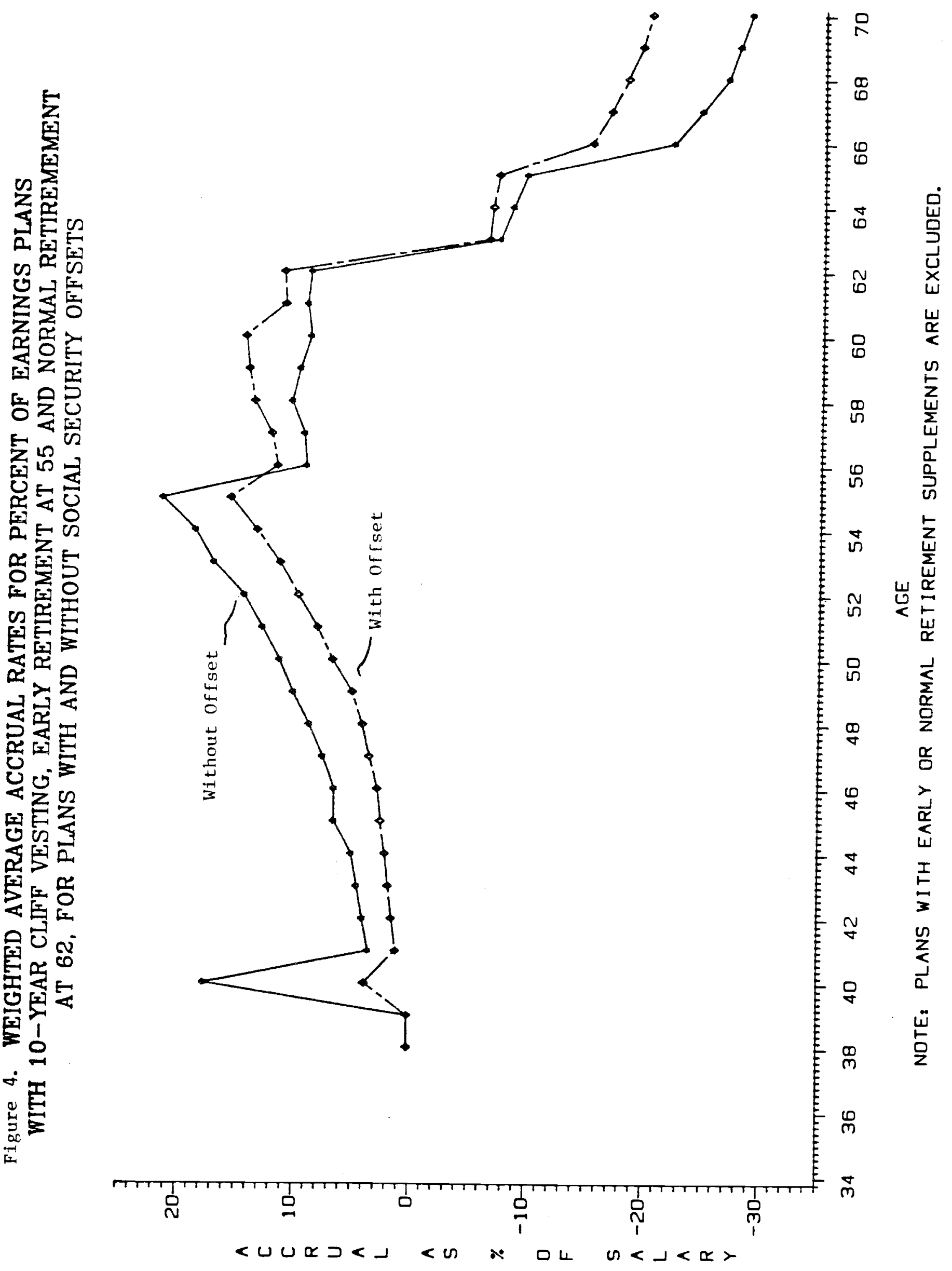
with early retirement at 55 and normal retirement at $65 \mathrm{is} .071$, as shown in table 1 above. It can be seen in table 4 that that accrual is over 12 percent for plans without a social security offset while it is less than 2 percent for plans with a offset.

\section{Accrual Ratios by Industry and Occupation}

\section{Industry}

Accrual profiles for selected industries are shown in table 5. For purposes of comparison and for ease of exposition, profiles are presented only for plans with early retirement at 55 although profiles for three normal retirement ages, 55, 62, 65, are shown. The most apparent difference among industries is in the proportion of plans with particular early and normal retirement ages. For example, in retail trade and services almost all plans have normal retirement at 65 , with only a few plans with early retirement at 55 or 62. On the other hand, almost 62 percent of plans in transportation have early and normal retirement at 55, with approximately 20 percent of plans showing normal retirement at 62 and 20 percent at 65 . In manufacturing, 66 percent of plans have normal retirement at 65,28 percent at 62 , and about 6 percent at 55 .

But among plans with the same early and normal retirement age, table 5 indicates little difference in average accrual profiles across industries. Table 6 isolates accrual ratios at critical ages, in particular before and after the age of early retirement and before and after the age of normal retirement. Averages are only presented for cells with more than 10 plans. Two dashes indicate that there were fewer than 10. The cell was left blank if the corresponding age did not represent a critical age for the plan in question. 


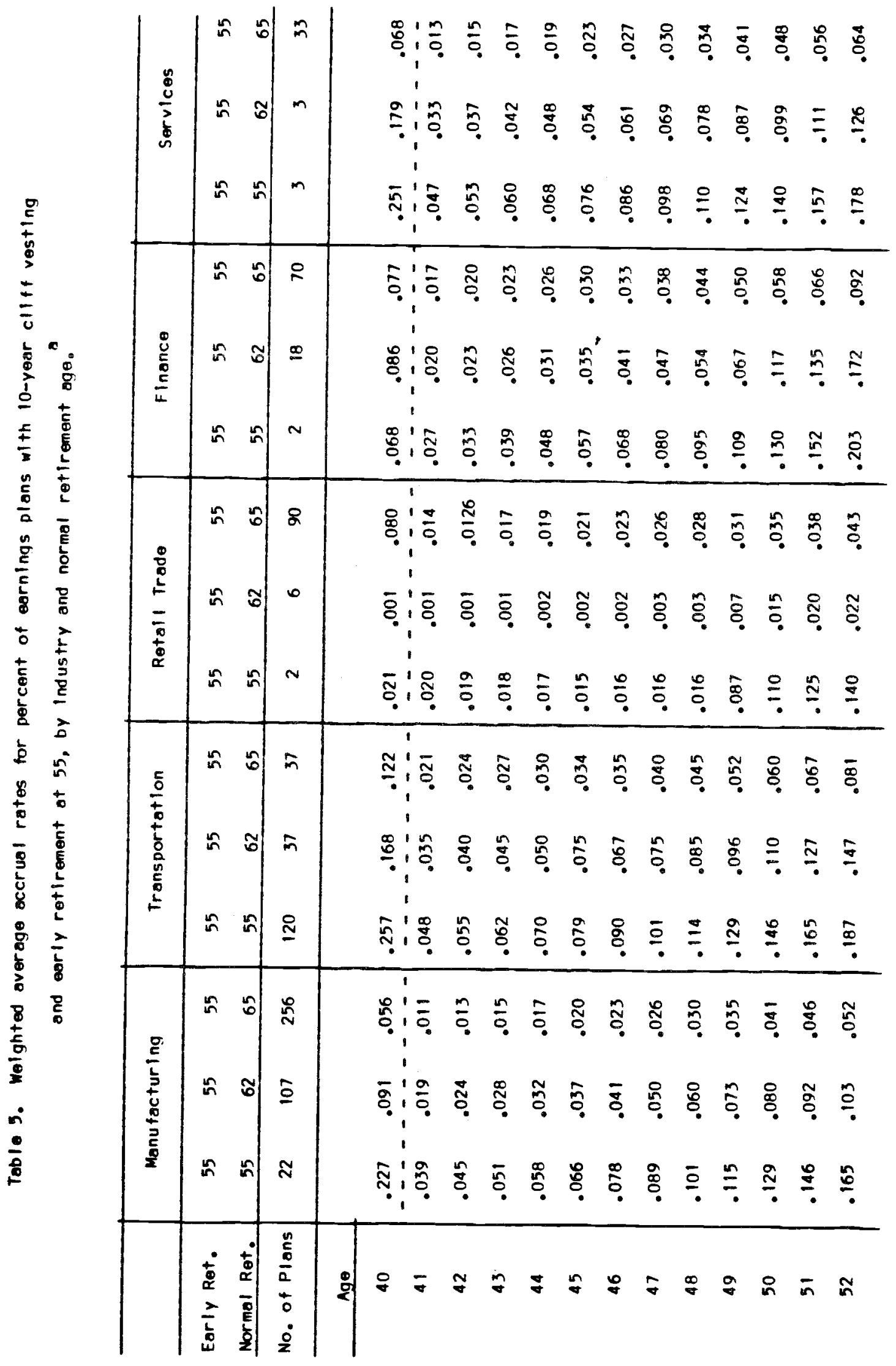




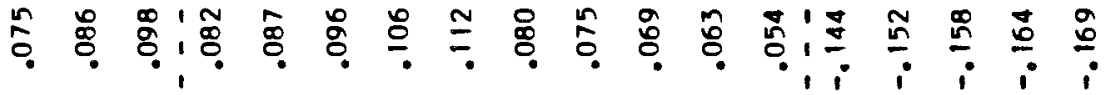

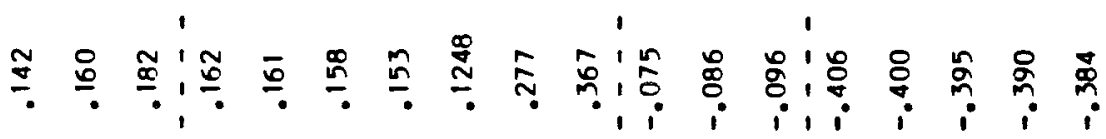

芩

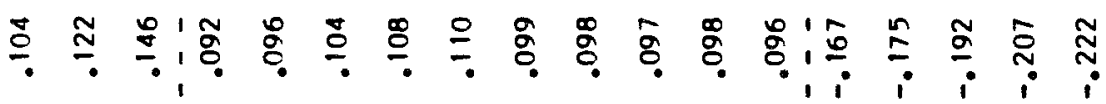

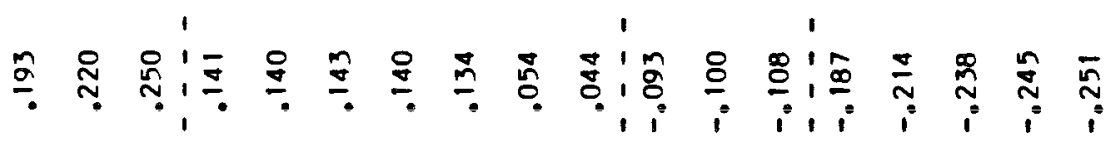

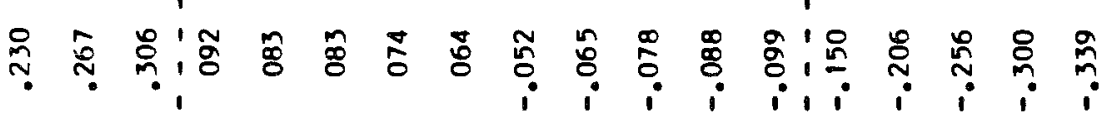

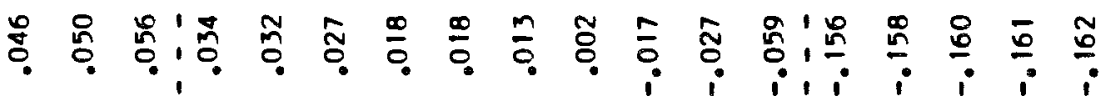

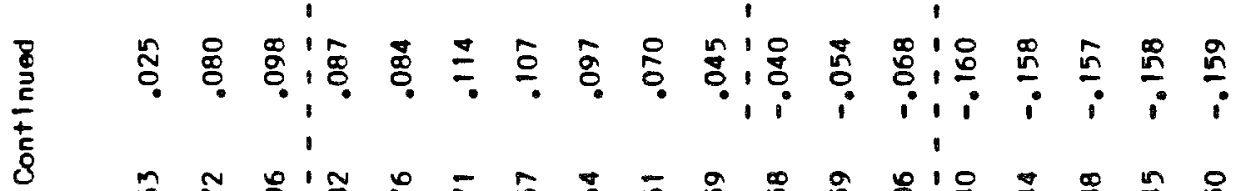

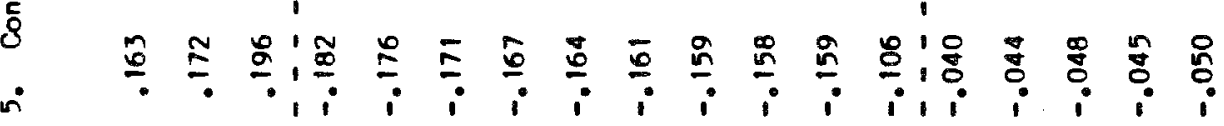

$\frac{0}{2}$

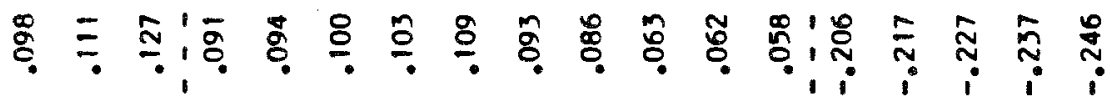

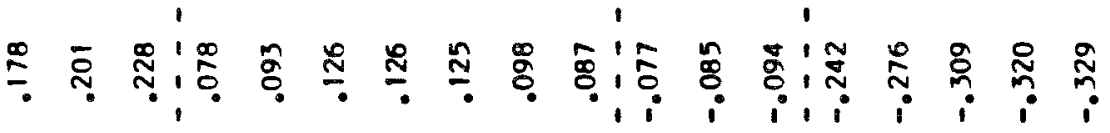

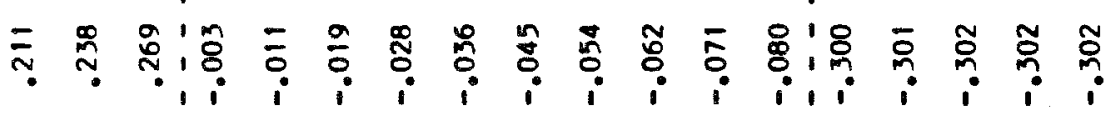

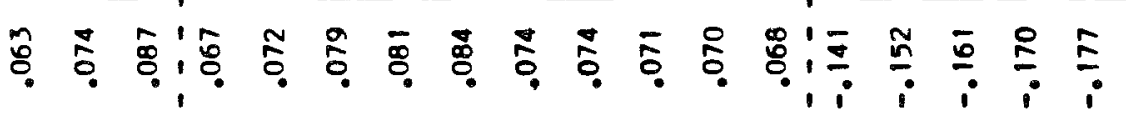

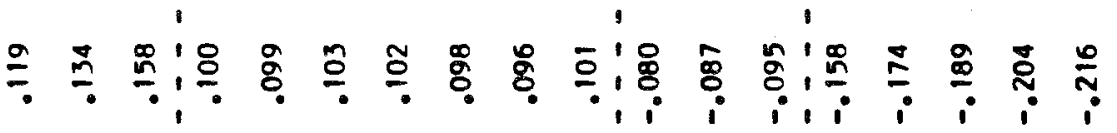

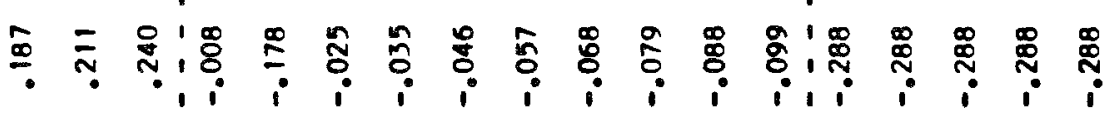

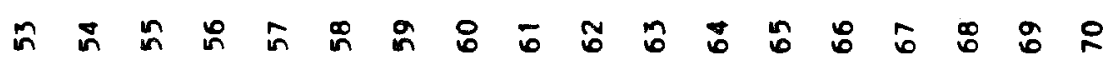


Table 6. Welghted average accrual rates at selected ages for percent of earnings plans with 10-year cllft vesting early retirement ot 55, early and normal retirement oges and industry.

\begin{tabular}{|c|c|c|c|c|c|}
\hline \multirow{2}{*}{$\begin{array}{c}\text { Early and } \\
\text { Norma! } \\
\text { Retirement } \\
\text { Ages, } \\
\text { Age }\end{array}$} & \multicolumn{5}{|c|}{ Industry } \\
\hline & $\begin{array}{l}\text { Manufac- } \\
\text { turing }\end{array}$ & $\begin{array}{c}\text { Trans- } \\
\text { portation }\end{array}$ & $\begin{array}{l}\text { Retall } \\
\text { Trode }\end{array}$ & Financo & Services \\
\hline \multicolumn{6}{|l|}{$55-55$} \\
\hline 40 & .227 & .257 & --- & -- & $-\cdots$ \\
\hline 55 & .240 & .269 & $-\infty$ & -- & $-\infty$ \\
\hline 56 & -.008 & -.003 & -- & $m$ & $-\infty$ \\
\hline \multicolumn{6}{|l|}{62} \\
\hline \multicolumn{6}{|l|}{63} \\
\hline 65 & -.099 & -.080 & -- & $-\infty$ & $\cdots$ \\
\hline 66 & -.288 & -.300 & -- & --- & --- \\
\hline 70 & -.288 &.- .302 & $\cdots$ & $-\infty$ & $-\infty$ \\
\hline \multicolumn{6}{|l|}{$55-62$} \\
\hline 40 & .091 & .168 & $-m$ & .086 & --- \\
\hline 55 & .158 & .228 & $\cdots$ & .250 & -- \\
\hline 56 & .100 & .078 & -- & .141 & -- \\
\hline 62 & .101 & .087 & $\cdots$ & .044 & $-\infty$ \\
\hline 63 & -.080 & -.077 & $\cdots$ & -.093 & -- \\
\hline 65 & -.095 & -.097 & -- & -.108 & $-\infty$ \\
\hline 66 &. .158 & -.242 & $-\infty$ & -.187 & -- \\
\hline 70 & -.216 & -.329 & $-\infty$ & -.251 & $\cdots$ \\
\hline \multicolumn{6}{|l|}{$55-65$} \\
\hline 40 & .056 & .122 & .080 & .077 & .068 \\
\hline 55 & .087 & .127 & .056 & .146 & .098 \\
\hline 56 & .067 & .091 & .034 & .092 & .082 \\
\hline \multicolumn{6}{|l|}{62} \\
\hline \multicolumn{6}{|l|}{63} \\
\hline 65 & .068 & .058 & -.059 & .096 & .054 \\
\hline 66 & -.141 & -.206 &. .156 & -.167 &. .144 \\
\hline 70 & -.177 & -.246 & -.162 & -.222 & -.169 \\
\hline
\end{tabular}


Only in manufacturing and transportation were there a substantial number of plans with early and normal retirement at 55. In these two industries, the accrual profiles look very similar. Three industries had a significant number of plans with early retirement at 55 and normal retirement at 62 , and again there seems to be little noticeable difference among the plans by industry. All industries have plans with normal retirement at 65 . But even in this case, the profiles seem quite similar. The only possible exception seems to be retail trade, where pension accrual relative to the wage rate is less generous than in the other industry groups.

Nonetheless, a typical worker apparently faces a much greater incentive to leave the labor force early in some industries than in others. For example, a large proportion of workers covered by pensions in transportation would experience a 27 percent reduction in effective compensation by continuing to work between 55 and 56. While at 55 , pension accrual would be equivalent to about 27 percent of wage rates for many workers in this industry, if the worker continued in the labor force until age 66 , his annual loss in pension wealth would be equivalent to 30 percent of wage earnings at 66 . A large proportion of workers in manufacturing have plans with early retirement at 55 and normal retirement at 65. In this case, the accrual at 55 averages about 9 percent of the wage at 55 and declines only to about 7 percent of the wage by 65 . But then the accrual rate becomes negative, and if the worker were to continued in the labor force between 65 and 66 , the decline in pension accrual would amount to an effective reduction in compensation of about 21 percent.

\section{Occupation}

Among plans with the same early and normal retirement ages, the pension 
accrual ratios do not differ noticeably by occupation. Accrual ratios for professionals, clerical workers, and production workers are shown in table 7 for plans with early retirement at age 55 and 3 normal retirement ages--55, 62, and 65. Plans in the 55-65 group are graphed by occupation in figure 5. It seems clear from the table and the figure that given the age of normal retirement, there appears to be no substantial differences in accrual ratios by occupational group. Consider for example plans with normal retirement at age 55: at age 55, the accrual ratio is .29 for professionals, .25 for clerical workers, and .25 for production workers. Ât age 66 , the accrual ratio has aropped to -. 30 for professionals, -.30 for clerical workers, and -.29 for production workers. Similarly, close ratios are observed for the other two normal retirement ages. For example, at age 62 the accrual ratios for plans with normal retirement at 62 are .10 for professionals, .10 for clerical workers, and .10 for production workers. This is not to say that there are no differences in pension coverage by occupational groups. It simply says that conditional on having a plan with given early and normal retirement ages, the accrual ratios for the occupational groups are very similar. The data in table 7 may, however, be concealing intra industry variation in accrual profiles by occupation for given retirement ages. To address this potential ambiguity, accrual ratios for the same plans treated in table 7 are presented in table 8 but only for manufacturing. But here again there is very little difference in the accrual profiles by occupation. Consider, for example, the drop in accrual ratios between age 55 and 66 . For plans with normal retirement at age 55 , the decline is $.58(.287$ minus -.295) for professionals, .51 for clerical workers, and .50 for production workers. Analogous declines are .29 for professionals, .30 for clerical 
Table 7. Weighted overage accruel rates for percent of earnings plans - ith 10-year clltt vesting and early retirement of oge 55, by normal retirement oge and accupation."

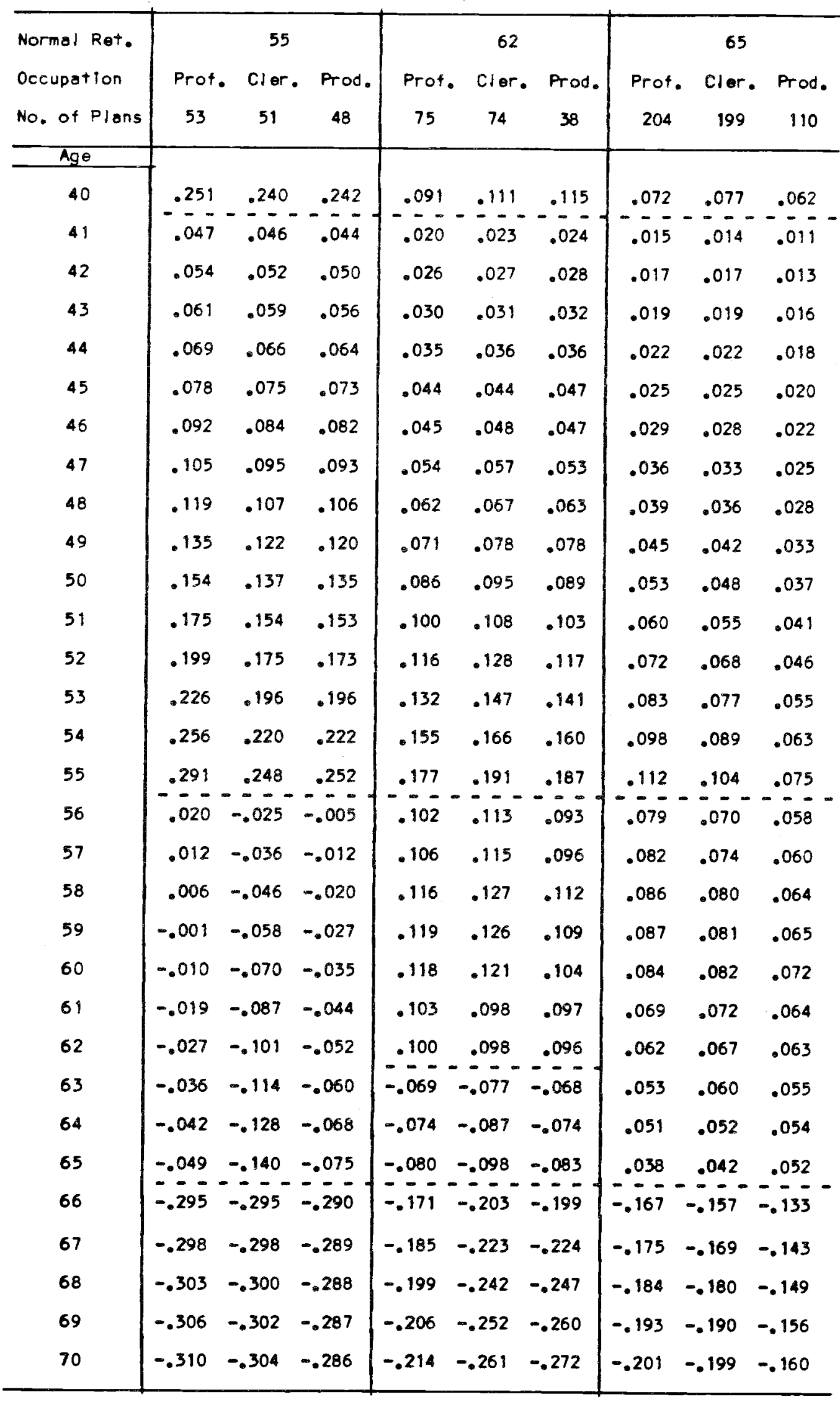

a. Plans with carly or normal retirement supplements or excluded. 

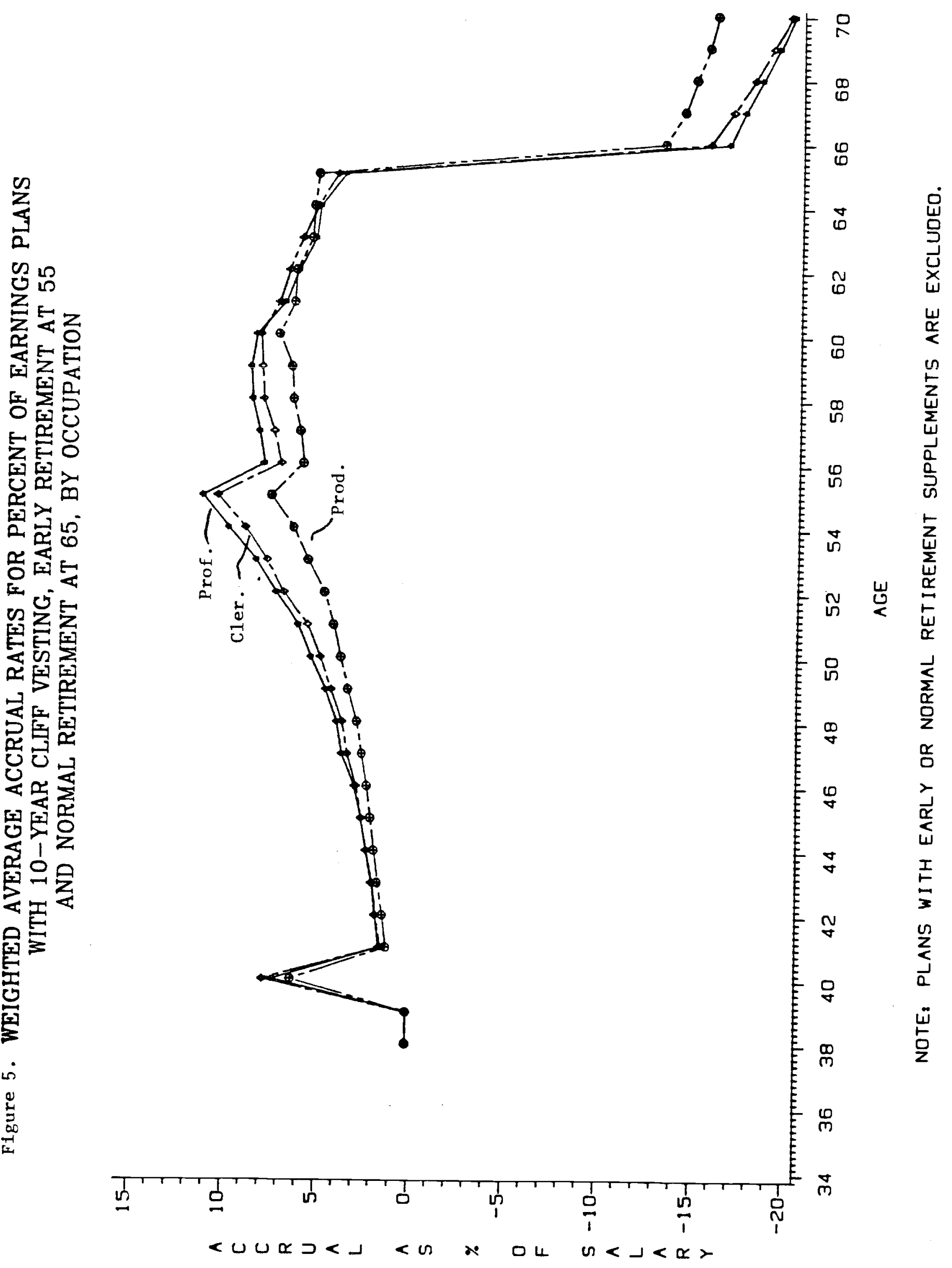
Table 8. Welghted average accrual rates for percent of earnings plans w ith 10-year clitt vesting and early retirement at oge 55, by normal retirement oge and occupetion, for manufacturing."

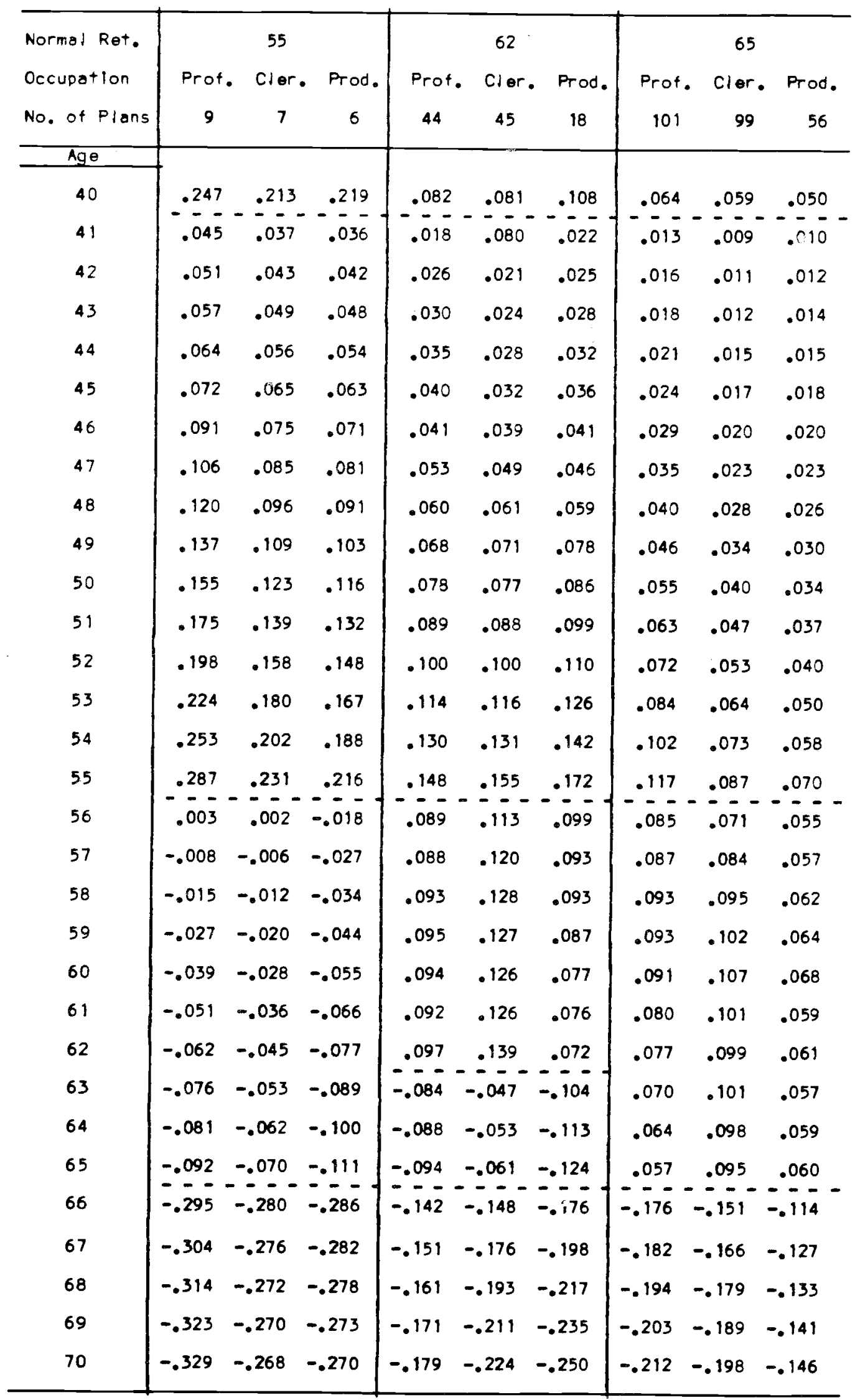

- Plans with carly or normal retirement supplements ore excluded. 
workers, and .35 for production workers, respectively, in plans with normal retirement at 62. Only among plans with normal retirement at age 65 is there a noticeable difference in the accrual ratios by occupation. In this case, the drop between age 55 and age 66 is .29 for professionals, .25 for clerical workers, but somewhat less than .18 for production workers. Thus we conclude that differences in pension accrual ratios by occupation are primarily due to different plan types or to differences in early and normal retirement, given the general type of plan. Production workers, for example, are more likely to have flat benefit plans than professionals.

\section{E. The Effect of Alternative Post-Normal-Retirement Provisions on}

\section{Pension Accrual}

Accrual ratios for percent of earnings plans with early retirement at 55 are shown in table 9 for selected normal retirement ages and for alternative post-normal retirement provisions. The post-normal retirement provisions have been grouped into five categories:

(1) Full Credit, Deferred: plans providing full credit according to the standard formula for years worked past the age of normal retirement, but with benefits beginning only after retirement.

(2) No Credit, Deferred: plans with no credit given for work after the the age of normal retirement and with benefits beginning only after retirement.

(3) No Credit, Immediate Payout or Actuarial Increase: plans with no credit given for additional work after the age of normal retirement, but with benefits beginnning immediately or increased actuarially until benefits are taken. 


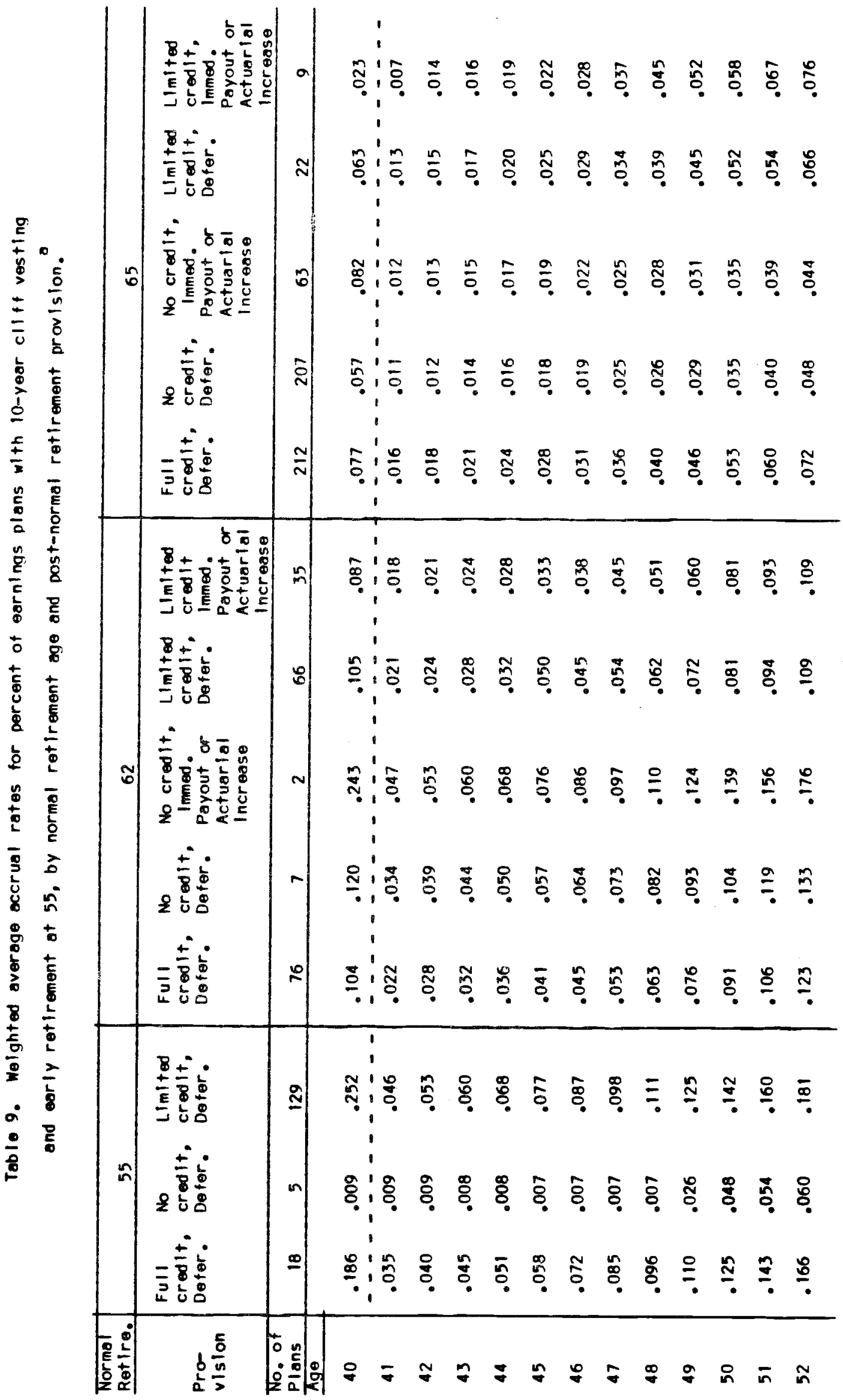




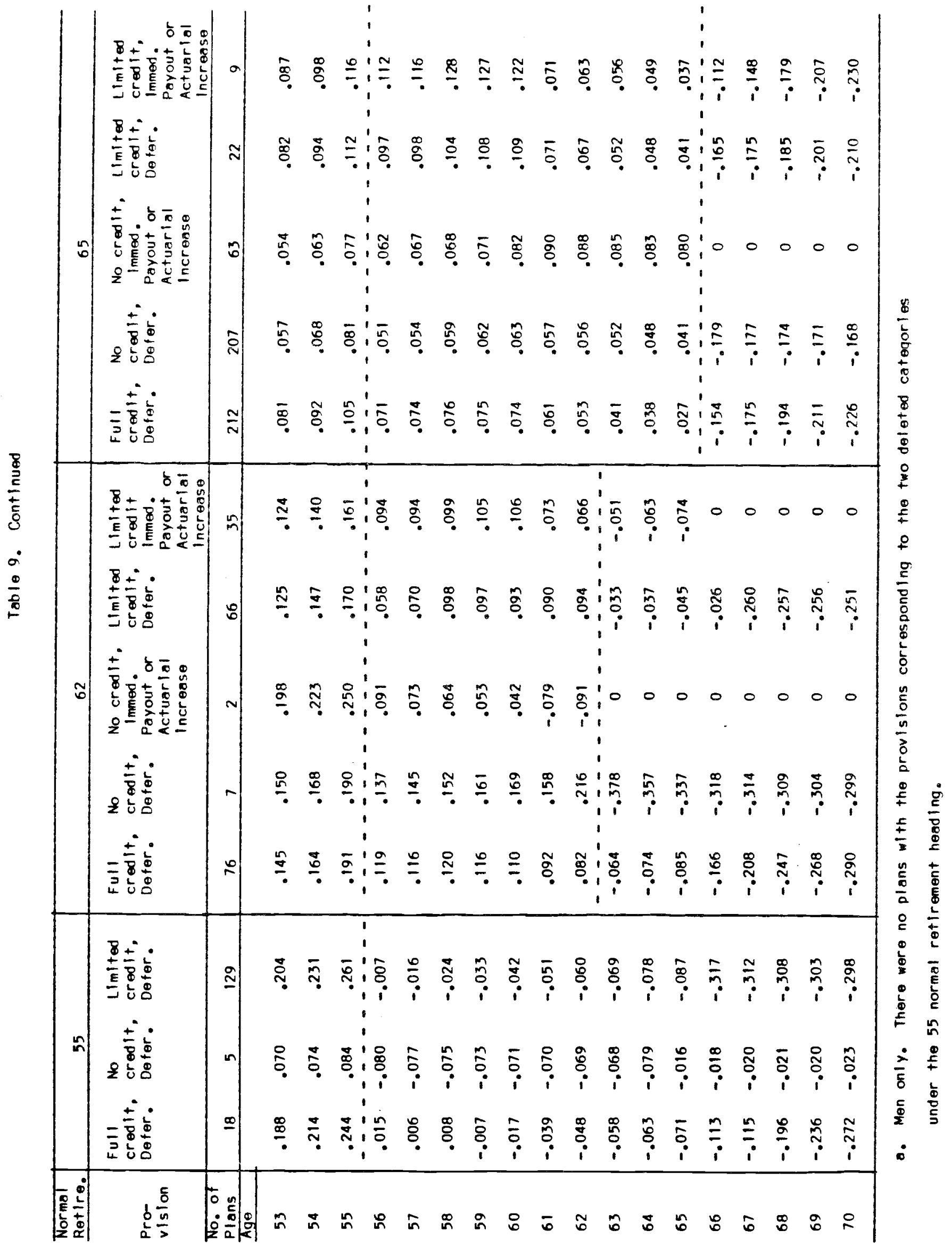


(4) Limited Credit, Deferred: plans with limited credit given for work after the age of normal retirement or with full credit for service post normal retirement up to a specified age or number of years; benefits are deferred in these plans until retirement.

(5) Limited Credit, Immediate Payout or Actuarial Increase: plans with provisions analogous to the third category above but with limited credit rather than no credit.

With the exception of plans of type (3), these provisions typically lead to very negative accrual ratios after the age of normal retirement. Table 9 compares accrual ratios across these 5 types of plans with varying post normal retirement benefit porvisions. The table examines alternative normal retirement ages, with early retirement occurring at 55. The figures in table 9 are somewhat surprising, indicating quite negative accrual ratios for plans that fully credit post normal retirement service; indeed, in certain cases, these negative accrual ratios are larger in absolute value than negative accrual ratios of plans that provide no credit.

To isolate the impact of the choice of post retirement provisions, accrual ratios for percent of earnings plans with early retirement at 55 and selected normal retirement ages were calculated first assuming that all of the plans had a full credit provision and second, assuming that all the plans had a no credit provision. These results are shown in table 10. The table indicates that the effect of crediting service after normal retirement depends importantly on the age of normal retirement. For plans with a normal retirement age of 55 negative accrual ratios are larger in absolute value under no crediting prior to age 66 and smaller in absolute value thereafter. 
Toble 10. Welghted average accrual rates for percent of earnings plans with 10-year cllft vesting ond erly retirement at 55, by norma! retirement oge, essuming fuld credit and no credit post retirement provislons.

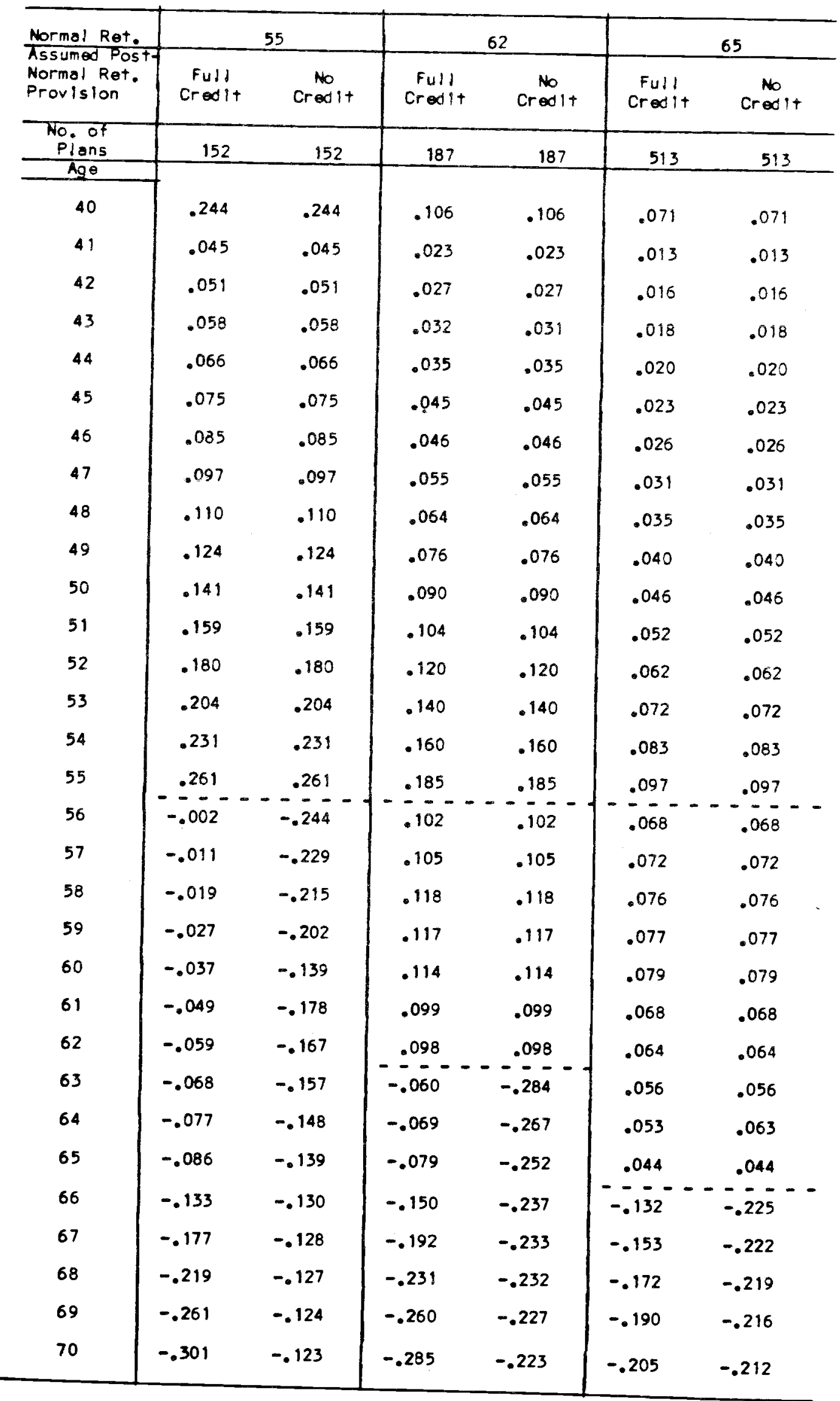




\section{F. Early and Normal Retirement Supplements}

Approximately 11.4 percent of plans have early and 7.5 have normal

retirement supplements. The typical normal retirement supplement provides an addition to otherwise calculated benefits if the individual postpones retirement until the normal retirement age. The typical early retirement supplement provides an addition to benefits if retirement occurs after the age of early retirement. The average accrual rates for percent of earnings and flat plans with supplements and with 10-year cliff vesting and early and normal retirement at 55 and 65 respectively, are shown in table 11 by type of supplement. There are only two plans in the category with only normal retirement supplements, but nonetheless the effect of the supplements can be seen in the first column of the table. The accrual rate jumps from about 8 percent of the wage at age 64 to 60 percent of the wage at age 65. Thus the supplement apparently provides a relatively strong incentive to remain with the firm until age 65 , but thereafter there is a sharp drop in the accrual rate to -18 percent. Accrual rates for plans with early retirement supplements are shown in the second column of the table. In this case there is a sharp increase in the accrual rate from .12 at age 54 to .44 at age 55, with a sharp drop thereafter. Again, the provision seems to provide a substantial incentive to remain with the firm to the age of early retirement, with a very substantial decline thereafter. Accrual rates for plans with both types of supplement are shown in the last column of the table. In this case there is a rather large spike at the age of early retirement, equal to 62 percent of the wage in that year, with a smaller but still noticeable spike at about the age of normal retirement.

Accrual rates for percent of earnings and flat plans with either type 
Table 11. Welghted average accrual rates for percent of earnings and flat plans with 10-year clift vesting, early and normal retirement at 55-65, and early or normal retirement supplement, by type of supplement.

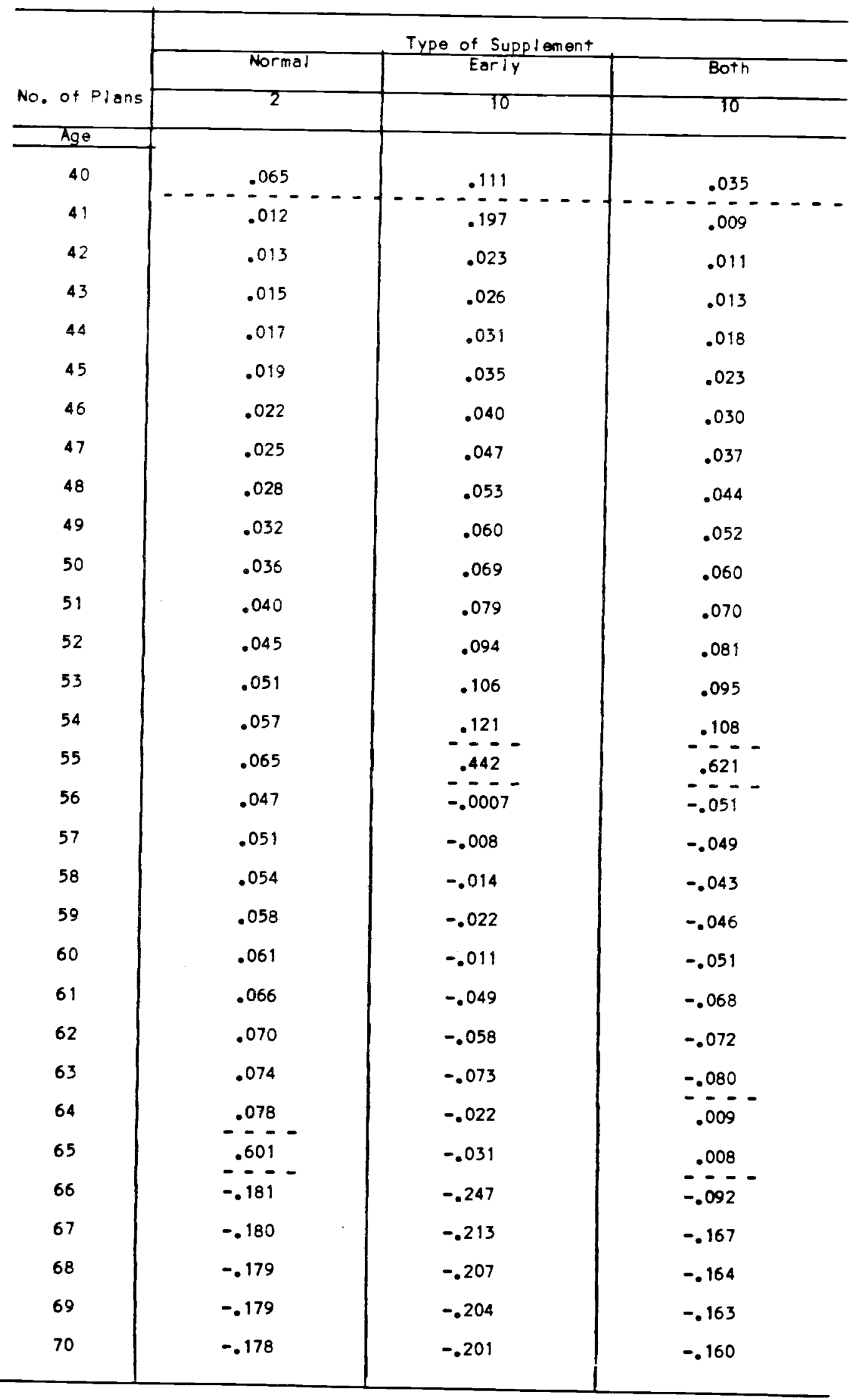


of supplement are shown in table 12 for selected early and normal retirement ages. The spikes in the accrual rates are highlighted with dashed lines. Consider for example plans with early retirement at age 55. The spike created by the early retirement supplement is from .22 to .39 for plans with normal retirement at 55 , from .12 to .50 for plans with normal retirement at 60 , and from .11 to .48 for plans with normal retirement at 65 . Of the 56 plans with normal retirement at age 60 , the pension accrual rate at that age is on average equivalent to 100 percent of the wage rate. Similar discontinuities in the accrual ratios are evident for plans with other early and normal ietirement ages. For example, of plans with early and normal retirement at age 60 , the accrual rate at that age is equivalent to 64 percent of the annual wage for persons aged 60. Thus these special supplements create very significant one-time additions pension wealth and therefore provide potentially very important incentives to remain with the firm until the age that the special supplement is awarded. The special supplements also further dramatize the wide variation in the incentive effects implicit in the provisions of private pension plans.

\section{Flat Benefit Plans}

Accrual ratios for flat benefit plans with selected early and normal retirement are shown in table 13. This table can be compared to table 1 above which presents comparable numbers for percent of earnings plans. The accrual profiles for flat plans with early-normal retirement at ages 55-55, 55-50, 55-65 are shown graphically in figure 6. In general, the accrual profiles for the flat benefit plans look quite similar to those for percent of earnings plans. 
Table 12. Welghted average accrual rotes for percent of earnings and flat plans with 10-year clitf vesting and early or normal retirement supplements, by early and normal retirement oges.

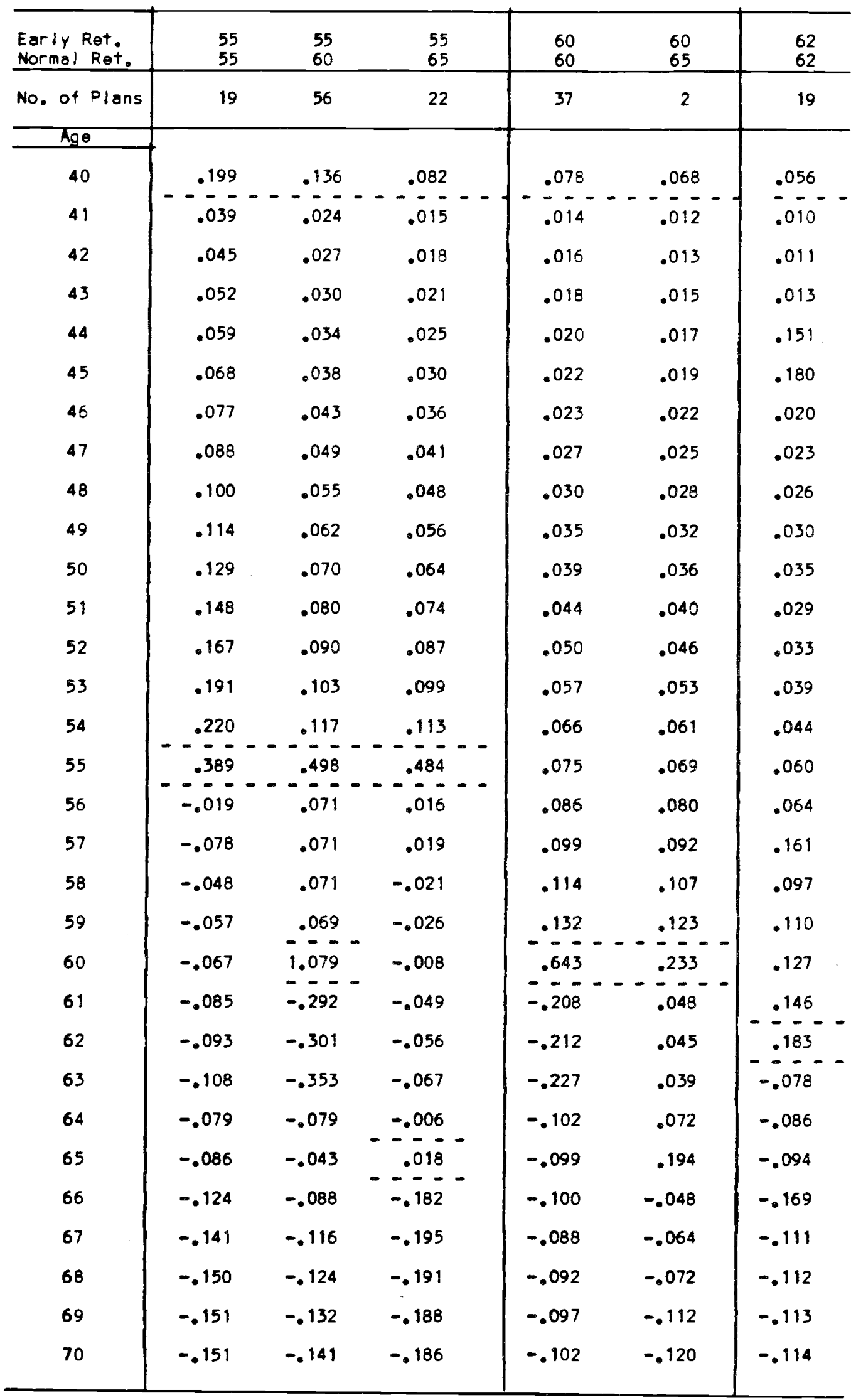

a. There are no plans in the 62-65 or in the 65-65 early-normal retirement groups. 
Table 13. Weighted average accrual rates for flat rate plans with 10-year clitf vesting, by early and normal retirement age.a

\begin{tabular}{|c|c|c|c|c|c|c|c|c|}
\hline $\begin{array}{l}\text { Early Ret. } \\
\text { Normal Ret. }\end{array}$ & $\begin{array}{r}55 \\
55 \\
\end{array}$ & $\begin{array}{l}55 \\
60 \\
\end{array}$ & $\begin{array}{l}55 \\
65 \\
\end{array}$ & $\begin{array}{l}60 \\
60 \\
\end{array}$ & $\begin{array}{l}60 \\
65 \\
\end{array}$ & $\begin{array}{l}62 \\
62 \\
\end{array}$ & $\begin{array}{l}62 \\
65 \\
\end{array}$ & $\begin{array}{l}65 \\
65 \\
\end{array}$ \\
\hline No. of Plans & 3 & 90 & 106 & 10 & 48 & 3 & 17 & 14 \\
\hline \multicolumn{9}{|l|}{ Age } \\
\hline $\begin{array}{l}40 \\
41\end{array}$ & $\frac{.304}{.052}$ & $-\frac{.104}{.027}$ & $\begin{array}{l}.070 \\
.012\end{array}$ & $\frac{.022}{.004}$ & $\begin{array}{l}.046 \\
-.008\end{array}$ & $\frac{.033}{.006}$ & 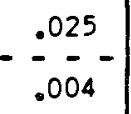 & $\frac{.019}{.006}-$ \\
\hline 42 & .059 & .031 & .013 & .004 & .009 & .007 & .005 & .006 \\
\hline 43 & .066 & .035 & .015 & .005 & .010 & .007 & .006 & .006 \\
\hline 44 & .075 & .039 & .017 & .006 & .012 & .008 & .007 & .007 \\
\hline 45 & .084 & .044 & .019 & .006 & .013 & .009 & .007 & .007 \\
\hline 46 & .096 & .049 & .022 & .007 & .015 & .010 & .008 & .007 \\
\hline 47 & .108 & .052 & .025 & .029 & .017 & .011 & .009 & .008 \\
\hline 48 & .123 & .058 & .029 & .053 & .019 & .013 & .011 & .009 \\
\hline 49 & .139 & .064 & .032 & .063 & .022 & .015 & .012 & .009 \\
\hline 50 & .158 & .073 & .037 & .067 & .025 & .016 & .013 & .010 \\
\hline 51 & .180 & .093 & .042 & .079 & .028 & .018 & .015 & .011 \\
\hline 52 & .205 & .105 & .048 & .084 & .032 & .021 & .017 & .012 \\
\hline 53 & .235 & .121 & .054 & .098 & .037 & .024 & .020 & .014 \\
\hline 54 & .269 & .138 & .062 & .110 & .042 & .027 & .022 & .015 \\
\hline 55 & 308 & .163 & .073 & .150 & .048 & .030 & .025 & .017 \\
\hline 56 & -.129 & .079 & .052 & .171 & .055 & .035 & .028 & .018 \\
\hline 57 & -.119 & .077 & .055 & .189 & .063 & .040 & .032 & .020 \\
\hline 58 & -.118 & .095 & .058 & .228 & .073 & .045 & .037 & .030 \\
\hline 59 & -.117 & .105 & .060 & .258 & .084 & .052 & .043 & .036 \\
\hline 60 & -.117 & .105 & .061 & .285 & .101 & .059 & .050 & .042 \\
\hline 61 & -.263 & -.029 & .050 & .005 & .061 & .068 & .058 & .042 \\
\hline 62 & -.253 & -.036 & .050 & -.012 & .062 & .078 & .068 & .049 \\
\hline 63 & -.244 & -.052 & .049 & -.042 & .063 & -.014 & .067 & .058 \\
\hline 64 & -.235 & -.091 & .049 & -.058 & .034 & -.015 & .066 & .069 \\
\hline 65 & $\begin{array}{l}-.227 \\
---.\end{array}$ & $\begin{array}{l}=104 \\
=-.\end{array}$ & .049 & $\begin{array}{l}-.079 \\
--\end{array}$ & .069 & $=.017$ & $\therefore .063$ & $\therefore 083$ \\
\hline 66 & -.280 & -.131 & -.091 & -.174 & -.074 & -.085 & -.037 & -.074 \\
\hline 67 & -.275 & -.164 & -.093 & -.267 & -.076 & -.083 & -.040 & -.074 \\
\hline 68 & -.271 &. .175 & -.096 & -.255 & -.078 & -.082 & -.042 & -.074 \\
\hline 69 & -.267 & -.181 & -.099 & -.246 & -.080 & -.081 & -.046 & -.074 \\
\hline 70 & -.263 & -.203 & -.102 & -.244 & -.083 & -.080 & -.049 & -.074 \\
\hline
\end{tabular}

- Plans with early or normal retirement supplements are excluded. 


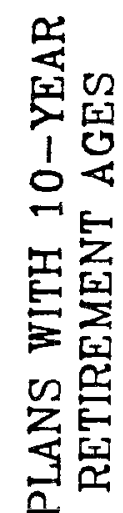

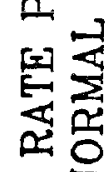

Ez

出是

里告

可兵

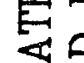

돌

交程

争焉

实

도도.

造告

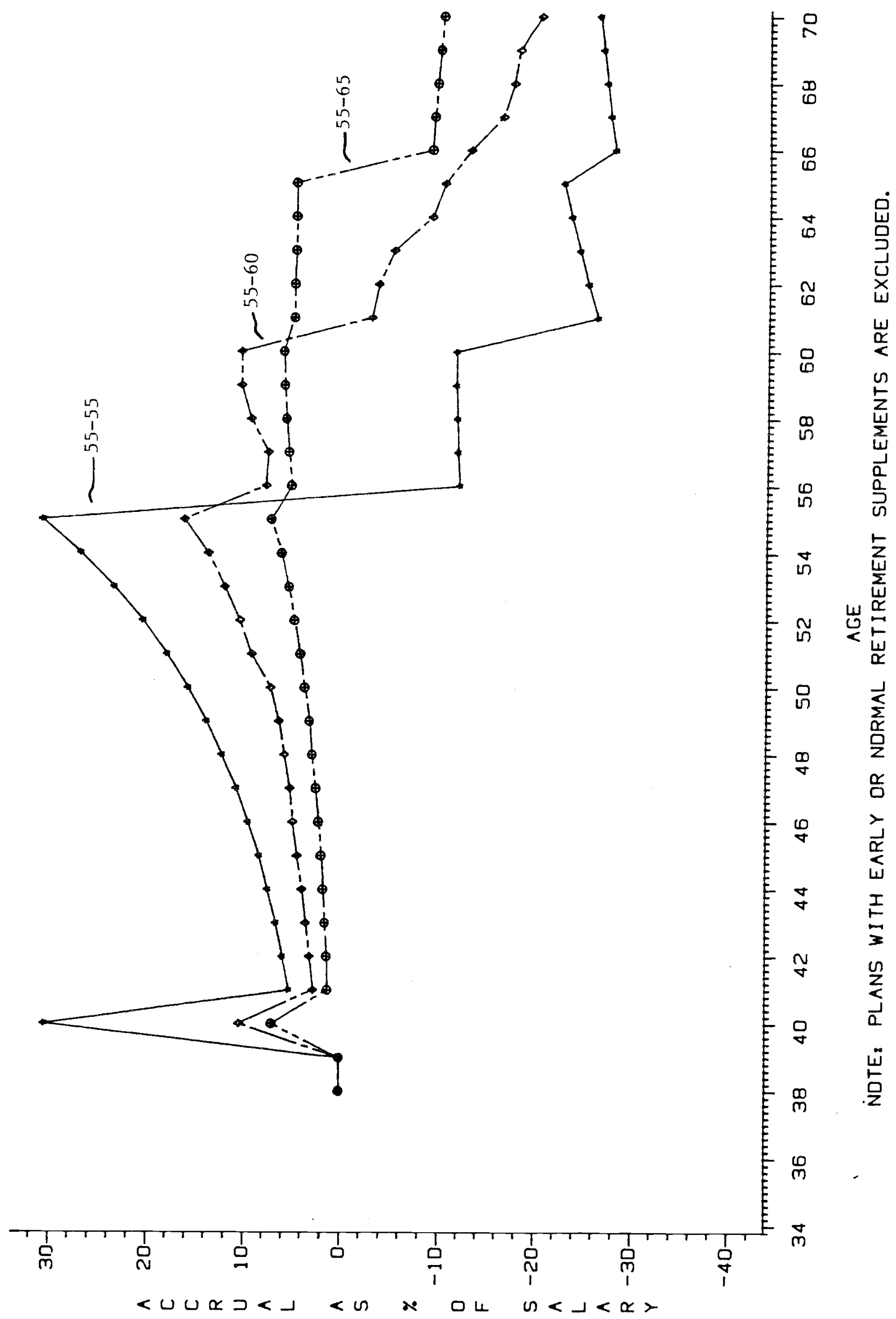


Recall that we have assumed that the flat benefit increases with the rate of inflation, assumed to be 6 percent annually in our calculations. While it is not possible to make comparisons for plans with each of the early and normal retirement combinations because of the relatively small sample sizes in some of them for flat benefit plans, for several early-normal retirement age combinations, there are rather large numbers of plans of both types, e.g., the combinations 55-60,55-65, and 60-65. The average decline in the accrual ratio between the age of early retirement to age 66 is. 30 for percent of earnings plans versus .39 for flat benefits plans in the case of the 55-60 retirement age combination. It is .25 versus .16 for the 55-65 combination, and .26 versus .17 for the 60-65 combination.

Accrual ratios at several critical ages for plans with early retirement at 55 and normal retirement at 65 are shown below for percent of earnings and flat benefit plans:

$\begin{array}{lccc}\text { Age } & \text { Percent of Earnings Plans } & \text { Flat Plans } \\ 40 & .071 & .070 \\ 55 & .097 & .073 \\ 56 & .068 & .052 \\ 65 & .044 & .049 \\ 66 & -.152 & -.091 \\ 70 & -.186 & -.102\end{array}$

The accrual rates for these plans are graphed in figure 7 . The evidence seems to indicate that the two types of plan provide rather similar incentive effects. The provisions of flat rate plans, like those of percent of earnings plans, also yield widely differing ratios, even among plans with the same early and normal retirement ages. Indications of the dispersion of the accrual ratios 


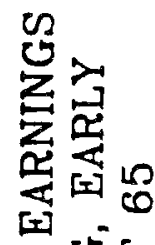
[5E E E Z E 논 空 도을 뚱 质弯 的至 110 엉 是是 止

论的

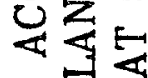
다 뙤 足 되 近 \& 炙 E 国咭 甹是 되 는 $\therefore$ $\overbrace{\substack{\infty \\ \infty}}^{0}$

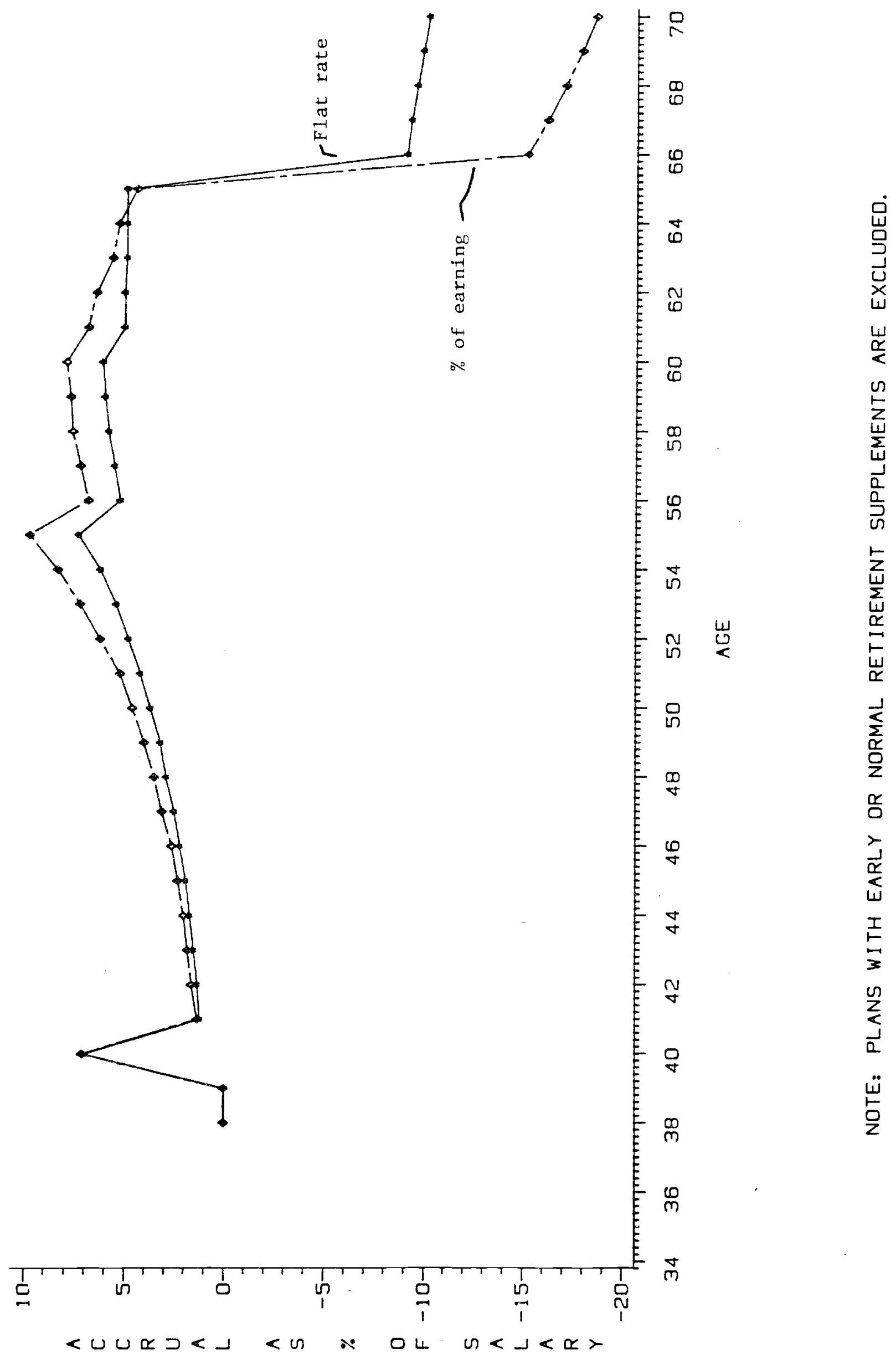


among flat plans with early and normal retirement at 55 and 65 respectively are shown in table 14 and in figure 8. While the average accrual rate at age 55 , for example, is 7 percent, the minimum value is 0 and the maximum 24 percent. Similarly at age 56, while the average is about 5 percent the maximum is 20 percent and the minimum about 0 . At 65 , the average is 5 percent, with a maximum of almost 33 percent and a minimum of about -20 percent. At 66 after the age of normal retirement, the average accrual rate is -9 percent, while the minimum is -56 percent and the maximum 0 . Thus the incentive for retirement varies widely among flat, as well as percent of earnings plans.

IV. The Pension Cost of Job Change

There are many ways to think about the effect of job change on pension accrual and the potential incentive effects of pension provisions on the job change decision. One approach is to consider the effect of job change on accrued pension wealth at the age of retirement, say the age of plan normal retirement. Another way is to consider the expected loss in future pension wealth from changing job as a proportion of expected future wages. We shall consider variants of both measures.

\section{A. If Change to a No-Pension Job}

Consider a person who starts a job at some age, say 31. Suppose that at a given subsequent age the person could change to another fob and obtain the same future wages as on the current job. His decision, assume, is either to stay on the current job until normal retirement, or to switch to the second job and stay on that one until the age of normal retirement. But suppose that the 
Table 14. Dispersion of accrual rates for table 11 plans with age 55 early retirement and age 65 normal retirement.

\begin{tabular}{|c|c|c|c|c|c|c|}
\hline & $\begin{array}{l}\text { Welghted } \\
\text { Average } \\
\text { Accrual } \\
\text { Ratios }\end{array}$ & $\begin{array}{l}\text { Median } \\
\text { Accrual } \\
\text { Ratios }\end{array}$ & $\begin{array}{l}\text { Minimum } \\
\text { Accrual } \\
\text { Ratios }\end{array}$ & $\begin{array}{l}\text { Maximum } \\
\text { Accrual } \\
\text { Ratios }\end{array}$ & $\begin{array}{l}\text { Lowest } \\
5+h \\
\text { Percen- } \\
\text { tille } \\
\end{array}$ & $\begin{array}{c}\text { Lorgest } \\
5+h \\
\text { Percen- } \\
+i l e \\
\end{array}$ \\
\hline No. of Plans & 106 & 106 & 106 & 106 & 106 & 106 \\
\hline \multicolumn{7}{|l|}{$\mathrm{Ag \theta}$} \\
\hline $\begin{array}{l}40 \\
41\end{array}$ & $-\frac{.070}{.012}=-$ & $-\frac{.073}{.013}$ & $-\frac{0}{0}-$ & $-\frac{.260}{.045}$ & $-\frac{0}{0}-$ & $-\frac{.157}{.027}-$ \\
\hline 42 & .013 & .015 & 0 & .050 & 0 & .030 \\
\hline 43 & .015 & .016 & 0 & .057 & 0 & .034 \\
\hline 44 & .017 & .018 & 0 & .064 & 0 & .038 \\
\hline 45 & .019 & $.02 \mathrm{i}$ & 0 & .072 & 0 & .043 \\
\hline 46 & .022 & .024 & 0 & .081 & 0 & .049 \\
\hline 47 & .025 & .027 & 0 & .091 & 0 & .055 \\
\hline 48 & .029 & .031 & 0 & .102 & 0 & .062 \\
\hline 49 & .032 & .035 & 0 & .115 & 0 & .071 \\
\hline 50 & .037 & .039 & 0 & .130 & 0 & .080 \\
\hline 51 & .042 & .045 & 0 & .147 & 0 & .092 \\
\hline 52 & .048 & .041 & 0 & .166 & 0 & .104 \\
\hline 53 & .054 & .058 & 0 & .187 & 0 & .119 \\
\hline 54 & .062 & .067 & 0 & .212 & 0 & .137 \\
\hline 55 & .073 & .077 & 0 & .240 & .006 & .157 \\
\hline 56 & .052 & .053 & -.006 & .195 & 0 & .123 \\
\hline 57 & .056 & .055 & -.007 & .192 & 0 & .121 \\
\hline 58 & .058 & .055 & -.010 & .189 & 0 & .125 \\
\hline 59 & .060 & .055 & -.013 & .183 & -.008 & .146 \\
\hline 60 & .061 & .056 & -.031 & .184 & -.024 & .173 \\
\hline 61 & .050 & .042 & -.217 & .204 & -.051 & .137 \\
\hline 62 & .050 & .040 & -.213 & .226 & -.066 & .148 \\
\hline 63 & .049 & .035 & -.209 & .400 & -.082 & .162 \\
\hline 64 & .049 & .034 & -.204 & .561 & -.093 & .169 \\
\hline 65 & .049 & .029 & -.198 & .328 & -.101 & .184 \\
\hline 66 & -.091 & -.067 & -.560 & 0 & -.275 & 0 \\
\hline 67 & -.093 & -.073 & -.552 & .008 & -.291 & 0 \\
\hline 68 & -.096 & -.079 & -.545 & .055 & -.287 & 0 \\
\hline 69 & -.099 & -.096 & -.536 & .045 & -.283 & 0 \\
\hline 70 & -.102 & -.101 & -.528 & .035 & -.286 & 0 \\
\hline
\end{tabular}


覓 吹最 足

空国 它国 울 《氠 난 은

동 틀 公是 的要

동 돈 定 唍 浖 这国 원영 足的 的完 星国陵 焉

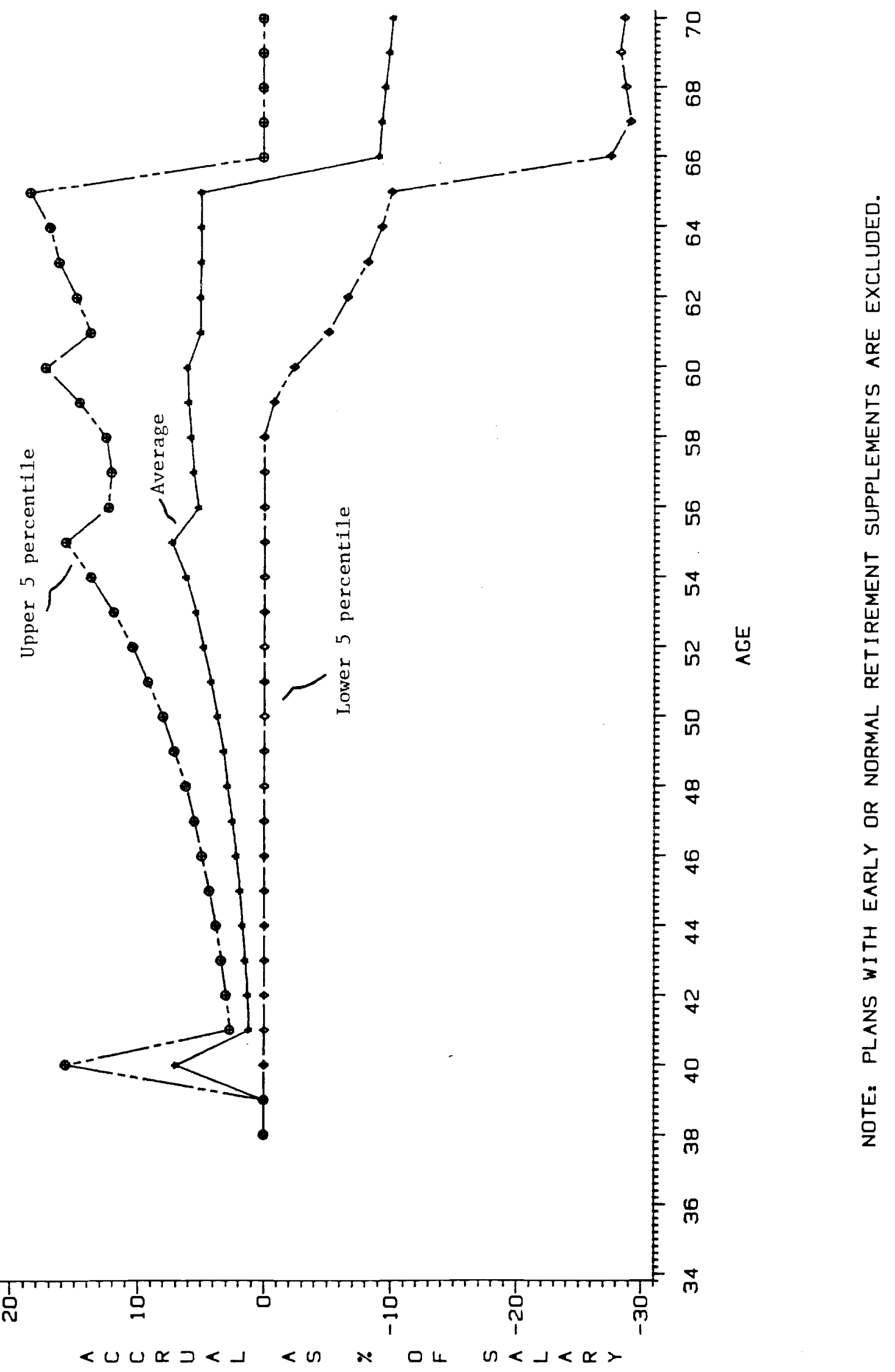


new job has no pension. Then the loss in pension wealth is equal to the pension wealth that the worker would accrue if he were to stay with the current employer until the age of normal retirement. This loss relative to the present value of expected future wages is shown in tables 15, 16, and 17. Table 15 assumes that an individual begins employment with the first firm at age 31 . Table 16 assumes a starting age of 41, and table 17 a starting age of 51 . The tables present these loss ratios by plan normal retirement age, and loss ratios are calculated through the age of normal retirement. To obtain a more concise picture of the losses, they are shown for selected ages of job change in table 18. For plans with normal retirement at 65 , the loss in pension wealth relative to expected wages is relatively small, between 4 and 6 percent for all ages of job change, with the exception of job change at age 59 when joining the firm at age 51 . In the latter case, the remaining working life of the individual is short and he is not yet vested. Thus the loss in potential pension accrual is relatively large compared to future earnings. Among plans with earlier normal retirement--55, 60 , or 62--the potential loss in future pension accrual is considerably larger, typically on the order of 8 to 20 percent of future earnings. The loss if one changes jobs just before normal retirement, however, is in some instances much larger than this, as high as 30 to 50 percent. For example, if at age 31 one enters a plan. with normal retirement at age 60 , the loss ratio if one changes job at 59 is 31 percent. If the individual enters at 51 and leaves at 59 , the loss is almost 50 percent.

The greater relative loss with earlier normal retirement is shown in figure 9, which presents loss ratios versus age for normal retirement at 55 and at 65 , starting at age 31 . The effect of starting age is shown graphically in 
Table 15. Loss in expected pension wealth if change to no-pension job, as percent of expected wages, by age of job change and by normal retirement age, starting initial job at age 31.

\begin{tabular}{|c|c|c|c|c|}
\hline Normal Ret. & 55 & 60 & 62 & 65 \\
\hline No. of Plans & 184 & 446 & 442 & 858 \\
\hline $\mathrm{Ag \theta}$ & & & & \\
\hline 31 & .072 & .055 & .048 & .026 \\
\hline 32 & .076 & .058 & .050 & .027 \\
\hline 33 & .080 & .061 & .053 & .028 \\
\hline 34 & .084 & .064 & .055 & .029 \\
\hline 35 & .089 & .067 & .058 & .030 \\
\hline 36 & .095 & .071 & .060 & .032 \\
\hline 37 & .101 & .075 & .064 & .033 \\
\hline 38 & .108 & .079 & .067 & .035 \\
\hline 39 & .116 & .084 & .071 & .037 \\
\hline 40 & .106 & .083 & .069 & .035 \\
\hline 41 & .111 & .087 & .072 & .037 \\
\hline 42 & .116 & .092 & .075 & .038 \\
\hline 43 & .122 & .097 & .078 & .040 \\
\hline 44 & .128 & .103 & .081 & .041 \\
\hline 45 & .134 & 108 & .083 & .043 \\
\hline 46 & .140 & .115 & .086 & .044 \\
\hline 47 & .145 & .121 & .089 & .046 \\
\hline 48 & .151 & .128 & .092 & .047 \\
\hline 49 & .156 & .135 & .094 & .048 \\
\hline 50 & .161 & .143 & .095 & .049 \\
\hline 51 & .163 & .152 & .097 & .050 \\
\hline 52 & .163 & .161 & .097 & .050 \\
\hline 53 & .154 & .171 & .096 & .050 \\
\hline 54 & .124 & .182 & .093 & .048 \\
\hline 55 & & .182 & .082 & .044 \\
\hline 56 & & .174 & .080 & .043 \\
\hline 57 & & 199 & .077 & .042 \\
\hline 58 & & .237 & .071 & .040 \\
\hline 59 & & .310 & .062 & .037 \\
\hline 60 & & & .031 & .032 \\
\hline 61 & & & .022 & .030 \\
\hline 62 & & & & .026 \\
\hline 63 & & & & .023 \\
\hline 64 & & & & .016 \\
\hline 65 & & & & \\
\hline
\end{tabular}


Table 16. Loss in expected pension wealth if change to no-pension job,

as percent of expected wages, by age of job change and by normal retirement age, starting initial job at age 41 .

\begin{tabular}{|c|c|c|c|c|}
\hline Normal Ret. & 55 & 60 & 62 & 65 \\
\hline No. of Plans & 57 & 349 & 546 & 1009 \\
\hline Age & & & & \\
\hline 41 & .079 & .064 & .062 & .034 \\
\hline 42 & .086 & .068 & .066 & .036 \\
\hline 43 & .093 & .073 & .071 & .038 \\
\hline 44 & .103 & .079 & .076 & .040 \\
\hline $4 \overline{5}$ & .114 & .085 & .082 & .043 \\
\hline 46 & .127 & .092 & .088 & .046 \\
\hline 47 & .143 & .101 & .096 & .050 \\
\hline 48 & .164 & .111 & .104 & .054 \\
\hline 49 & .191 & .122 & .114 & .058 \\
\hline 50 & .117 & .096 & .097 & .048 \\
\hline 51 & .121 & .100 & .102 & .049 \\
\hline 52 & .122 & .103 & .106 & .051 \\
\hline 53 & .119 & .105 & .110 & .052 \\
\hline 54 & .103 & .108 & .115 & .053 \\
\hline 55 & & .104 & .111 & .052 \\
\hline 56 & & .105 & .106 & .053 \\
\hline 57 & & .105 & .111 & .053 \\
\hline 58 & & .100 & .119 & .052 \\
\hline 59 & & .085 & .130 & .051 \\
\hline 60 & & & .132 & .047 \\
\hline 61 & & & .168 & .046 \\
\hline 62 & & & & .044 \\
\hline 63 & & & & .040 \\
\hline 64 & & & & .031 \\
\hline 65 & & & & \\
\hline
\end{tabular}


Table 17. Loss in expected pension wealth if change to no-pension job, as percent of expected wages, by age of job change and by normal retirement age, starting initial job at age 51 .

\begin{tabular}{|c|c|c|c|c|}
\hline Normal Ret. & 55 & 60 & 62 & 65 \\
\hline No. of Plans & 32 & 178 & 451 & 1287 \\
\hline $\mathrm{Age}$ & & & & \\
\hline 51 & .000 & .080 & .094 & .046 \\
\hline 52 & .000 & .091 & .105 & .051 \\
\hline 53 & .000 & .104 & .118 & .056 \\
\hline 54 & .000 & .122 & .134 & .062 \\
\hline 55 & & .146 & .150 & .069 \\
\hline 56 & & .178 & .169 & .079 \\
\hline 57 & & .229 & .203 & .090 \\
\hline 58 & & .313 & .251 & .104 \\
\hline 59 & & .482 & .325 & .122 \\
\hline 60 & & & .183 & .059 \\
\hline 61 & & & .246 & .060 \\
\hline 62 & & & & .059 \\
\hline 63 & & & & .055 \\
\hline 64 & & & & .044 \\
\hline 65 & & & & \\
\hline
\end{tabular}



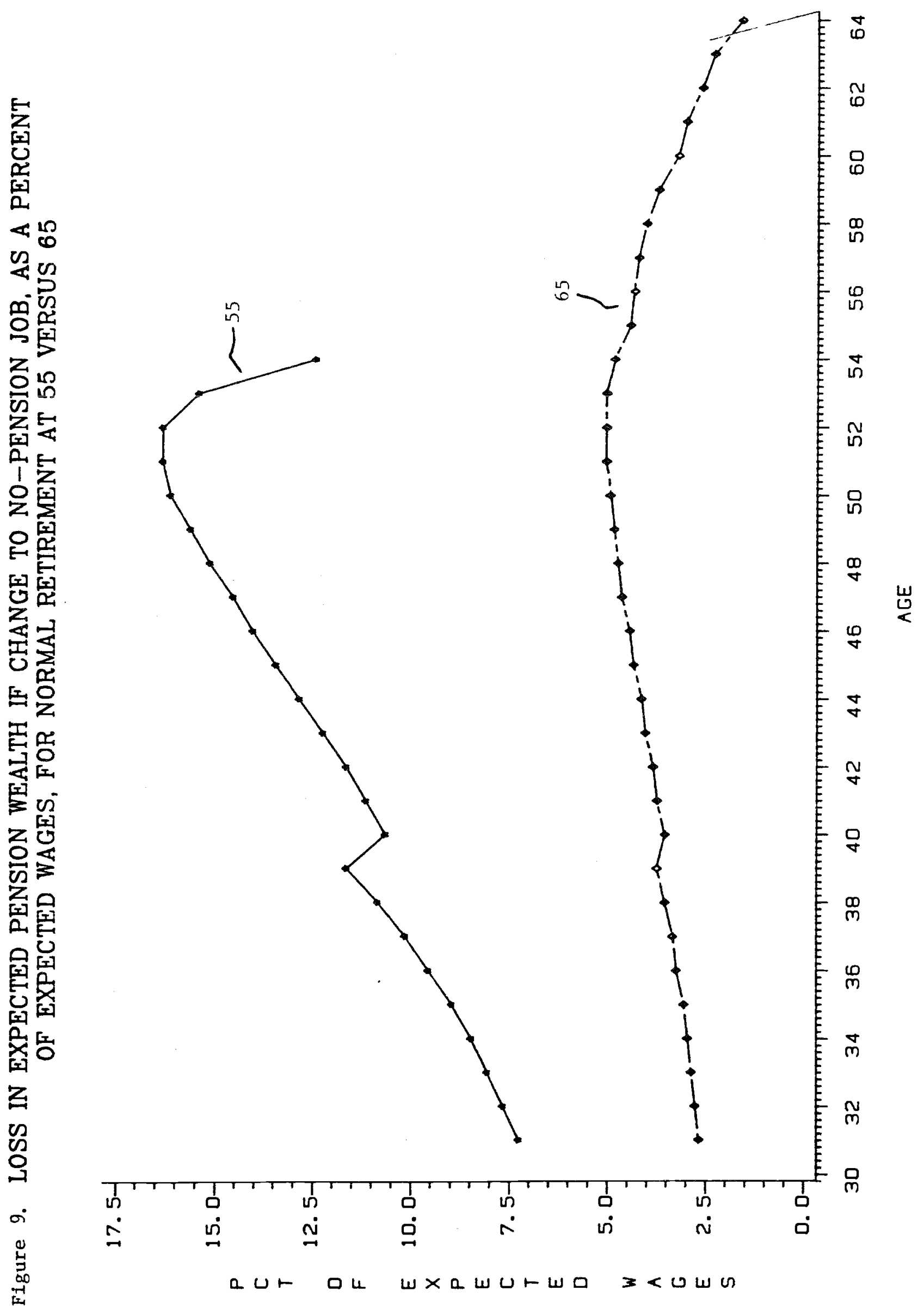
figure 10 for plans with normal retirement at 60 .

A limiting case of numbers like those presented in table 18 is the present discounted value of expected pension benefits at the age of hire as a proportion of expected wages at that time. These numbers of course indicate the cost to the employer of pension benefits versus wages if a person stays with the employer from the time of hire to the age of early or normal retirement. Such ratios are presented in table 19 by age of initial employment and plan normal retirement age. The ratios are presented first assuming that the individual remains with the firm until the age of early retirement and then assuming that the person remains until the age of normal retirement. It can be seen from the table that the present discounted value of pension versus wage compensation is small on average, ranging from about 2 percent to about 10 percent. The average proportion of compensation in pension benefits is typically larger the later the age of initial employment. For example, the ratio of pension benefits to wages for plans with normal retirement at 62 is .049 if one enters the firm at 31 and stays to the age of normal retirement. The ratio is .062 if one enters at 41 , and .094 if one enters at 51. It is important to understand that while these ratios may appear relatively small, the pattern of pension accrual may still have a very substantial effect on worker labor force participation, as demonstrated above.

And, possibly the most striking feature of these loss ratios, is the wide variation among plans. To demonstrate the dispersion, the mean loss ratio together with the minimum and maximum at each age, are shown in table 20 for plans with normal retirement at 65 and for persons who enter the firm at age 31. Up to age 55--which is the age of early retirement for a substantial proportion 

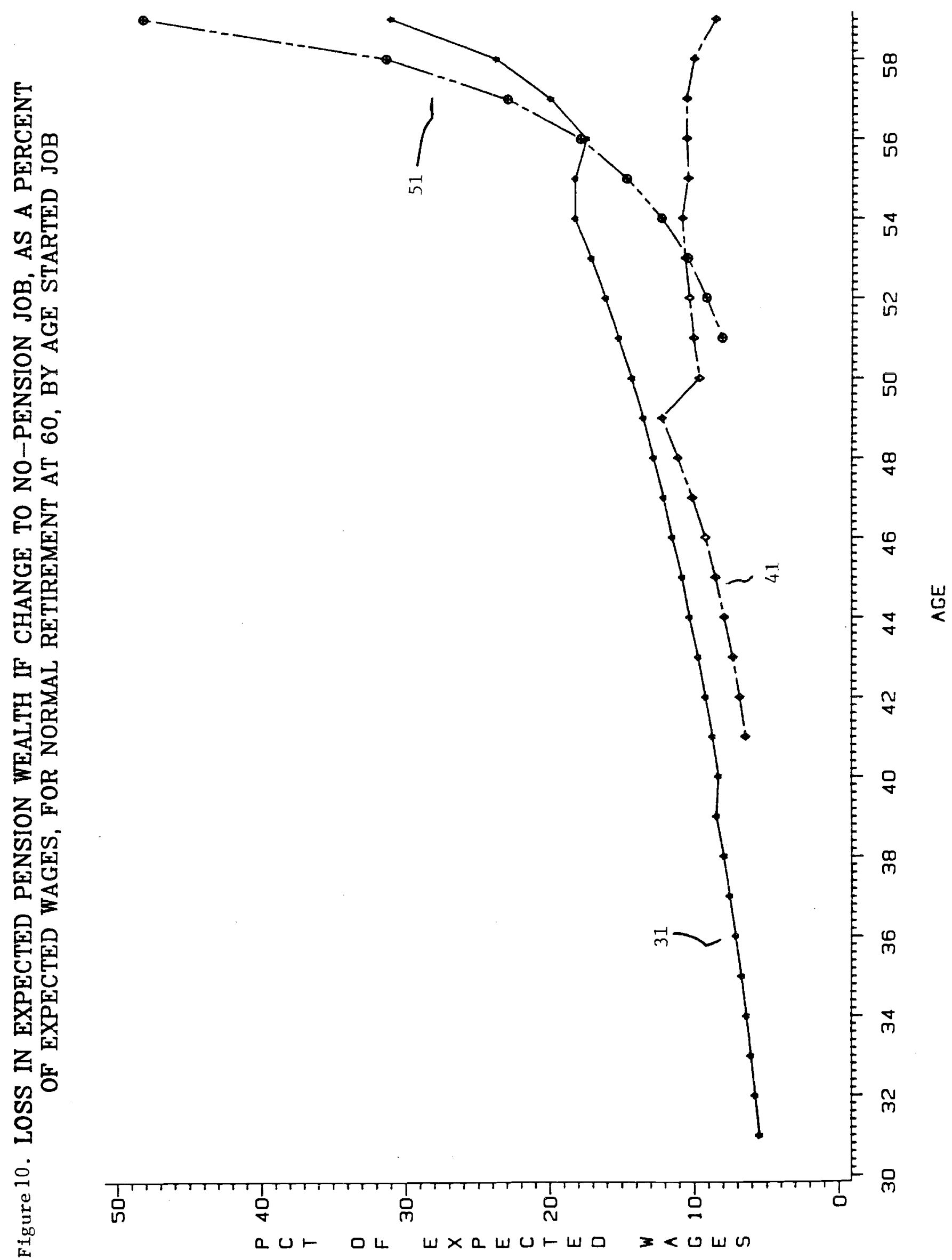
Table 18. Loss in expected pension wealth if change to no-pension job, as percent of expected wages by age

of job change, age of starting job, and age of normal retirement.

\begin{tabular}{|c|c|c|c|c|}
\hline \multirow{2}{*}{$\begin{array}{c}\text { Starting Age } \\
\text { and } \\
\text { Age }\end{array}$} & \multicolumn{4}{|c|}{ Plan Normal Retirement } \\
\hline & 55 & 60 & 62 & 65 \\
\hline \multicolumn{5}{|l|}{ 31: } \\
\hline 44 & .13 & .10 & .08 & .04 \\
\hline 49 & .16 & .14 & .09 & .05 \\
\hline 54 & .12 & .18 & .09 & .05 \\
\hline 59 & - & .31 & .06 & .04 \\
\hline \multicolumn{5}{|l|}{ 41: } \\
\hline 44 & .10 & .08 & .08 & .04 \\
\hline 49 & .19 & .12 & .11 & .06 \\
\hline 54 & .10 & .11 & .15 & .05 \\
\hline 59 & -- & .09 & .13 & .05 \\
\hline \multicolumn{5}{|l|}{ 51: } \\
\hline 44 & -- & -- & - & - \\
\hline 49 & - & - & -- & - \\
\hline 54 & - & .12 & .13 & .06 \\
\hline 59 & - & .48 & .33 & .12 \\
\hline
\end{tabular}

a. With expectations evaluated to plan normal retirement age. 
Table 19. Present discounted value of expected pension benefits as a proportion of expected wages, at age of hire, by age of hire and plan normal retirement age.

\begin{tabular}{|c|c|c|}
\hline $\begin{array}{l}\text { Age of Hire and } \\
\text { Plan Normal } \\
\text { Retirenent Age }\end{array}$ & $\begin{array}{c}\text { If Retire at } \\
\text { Early } \\
\text { Retirement Age }\end{array}$ & $\begin{array}{c}\text { If Retire ot } \\
\text { Normal } \\
\text { Retirement Age }\end{array}$ \\
\hline \multicolumn{3}{|l|}{ 31: } \\
\hline$A \|$ & .038 & .044 \\
\hline 55 & .072 & .072 \\
\hline 60 & .044 & .055 \\
\hline 52 & .045 & .049 \\
\hline 65 & .022 & .026 \\
\hline \multicolumn{3}{|l|}{ 41: } \\
\hline AlI & .042 & .049 \\
\hline 55 & .078 & .079 \\
\hline 60 & .060 & .064 \\
\hline 62 & .051 & .062 \\
\hline 65 & .027 & .034 \\
\hline \multicolumn{3}{|l|}{ 51: } \\
\hline All & .045 & .060 \\
\hline 55 & $\infty$ & -- \\
\hline 60 & .069 & .080 \\
\hline 62 & .054 & .094 \\
\hline 65 & .039 & .046 \\
\hline
\end{tabular}


Table 20. Dispersion of loss in expected pension wealth it change to no-pension job, for plans in table 15 with normal retirement at age 65 .

\begin{tabular}{|c|c|c|c|}
\hline$\overline{A g \theta}$ & Mean & Minimum & MaxTmum \\
\hline 31 & .026 & 0 & .098 \\
\hline 32 & .027 & 0 & .101 \\
\hline 33 & .028 & 0 & .105 \\
\hline 34 & .029 & 0 & .110 \\
\hline 35 & .030 & 0 & .115 \\
\hline 36 & .032 & 0 & .120 \\
\hline 37 & .033 & 0 & .125 \\
\hline 38 & .035 & 0 & .131 \\
\hline 59 & .037 & $\overline{0}$ & .137 \\
\hline 40 & .035 & -.010 & .139 \\
\hline 41 & .037 & -.009 & .145 \\
\hline 42 & .038 & -.008 & .152 \\
\hline 43 & .040 & -.007 & .158 \\
\hline 44 & .041 & -.005 & .166 \\
\hline 45 & .043 & -.003 & .173 \\
\hline 46 & .044 & -.004 & .182 \\
\hline 47 & .046 & -.005 & .190 \\
\hline 48 & .047 & -.005 & . 199 \\
\hline 49 & .048 & -.007 & .209 \\
\hline 50 & .049 & -.012 & .219 \\
\hline 51 & .050 & -.022 & .229 \\
\hline 52 & .050 & -.034 & .240 \\
\hline 53 & .050 & -.049 & .252 \\
\hline 54 & $\ldots \ldots .048$ & -.068 & .264 \\
\hline 55 & .044 & -.182 & .276 \\
\hline 56 & .043 & -.181 & .289 \\
\hline 57 & .042 & -.178 & .301 \\
\hline 58 & .040 & -.175 & .313 \\
\hline 59 & .037 & -.187 & .325 \\
\hline 60 & .032 & -.229 & .335 \\
\hline 61 & .030 & -.221 & .341 \\
\hline 62 & .026 & -.233 & .339 \\
\hline 63 & .023 & -.248 & .321 \\
\hline 64 & .016 & -.220 & .367 \\
\hline 65 & & & \\
\hline
\end{tabular}


of plans--the loss is close to zero for some plans and indeed is even negative for some. For other plans, however, the loss is very high, ranging up to 26 percent of future earnings at age 54. After 55, the maximum loss is typically over 30 percent, while the minimum is close to -20 percent at each age. Pension accrual after the age of early retirement is negative in many instances. For a member of such a plan, it would pay to leave this firm, taking early retirement benefits, and join another firm, assuming that one could join the second firm and obtain the same expected future wages.

B. Job Change and Pension Wealth at Age of Normal Retirement

Pension wealth at the age of normal retirement may be reduced very substantially by job change, as shown in Table 21 . A person who began work at 31 and changed to another job at 41 would have accrued, on average, on $1 y 72$ percent of the pension wealth of a person who began at 31 and remained in the same firm. If he changed jobs at 41 and again at 51 , he would accrue only 43 percent of the pension wealth of a person with no job change. This percent ranges from a low of 30 on average in transportation to 60 percent in construction. Thus the loss in pension wealth with job change seems to provide a potentially large incentive against job mobility.

Because some plans place a limit on years of service that are credited in calculating benefits, it may in some instances pay to change jobs and begin to accrue benefits in a new plan. This leads to ratios that are greater than one in a few instances. The minimum and maximum values, over all industries arise in anomalous plans, and these should not be given much weight; but they do suggest that there is substantial variation among plans in this respect, as well as in other respects discussed above. 
Table 21: Welghted average pension wealth (or ratio) at normal retirement, by age of initial employment, and by job change, and by industry, all plans.

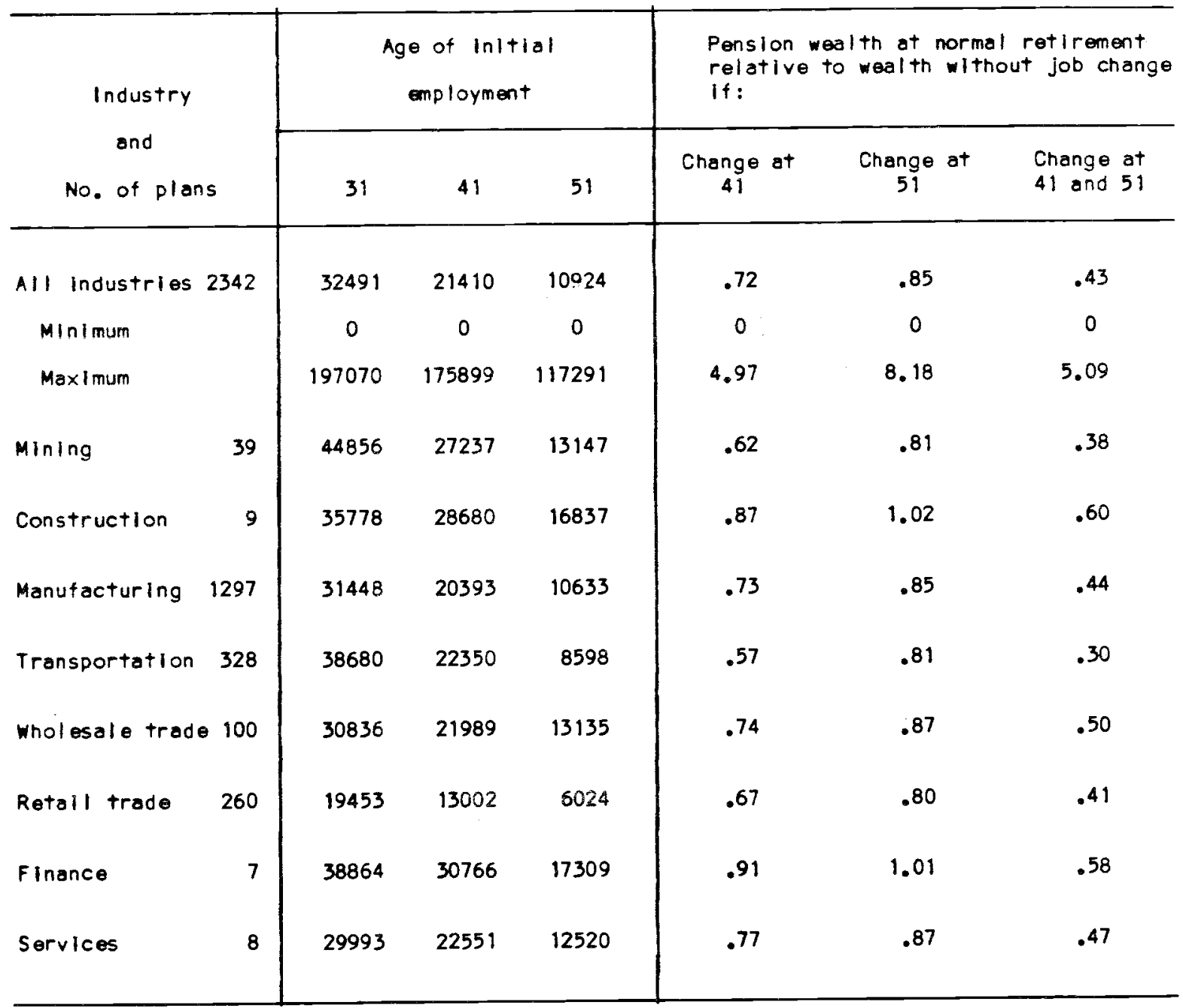




\section{Pension Accrual Ratios and Age of Initial Employment}

Pension accrual rates for percent of earnings plans with 10-year cliff vesting are shown in tables 22 and 23 for persons beginning employment at ages 41 and 51 respectively. The tables are analogous to table 1 above, presenting information by plan early and normal retirement ages. To provide an easier comparison of the accrual rates by starting age, accrual rates for selected ages are shown in table 24. The numbers are taken from table 1, table 22, and table 23. Accrual ratios for plans with early and normal retirement at 55 and 65 respectively are graphed in figure 1l. The accrual rate at vesting is the most important difference across initial employment ages. For example, as shown in table 24 , the accrual rate at vesting is . 24 for persons beginning employment at 31 , it is .62 for those beginning at age 41 , and .92 for those beginning at age 51. The difference is simply due to the fact that the later the age of initial employment, the nearer is the time of benefit receipt at the age of vesting. The accrual rate at vesting increases with age of initial employment for each early-normal retirement age category. Otherwise, the pattern of accrual rates does not vary by starting age, except that the absolute value of the rates, both positive and negative, is smaller as the age of initial employment increases. Again, this is simply because potential benefits are lower with later starting ages and, thus, potential losses after the age of early or normal retirement are smaller. Notice that the accrual rate after the age of 65 is negative in each case. Plan provisions typically make the age of early and normal retirement dependent upon age and years of service. Thus in practice, the ages of early and normal retirement are typically somewhat higher for persons beginning employment at age 51. But in no case is the age of normal retirement greater 
Table 22. Welghted average accrual rates for percent of earnings plans with 10-year clitf vesting, by early and normal retirement age, starting job at oge $410^{\circ}$

\begin{tabular}{|c|c|c|c|c|c|c|c|c|}
\hline $\begin{array}{l}\text { Early Ret. } \\
\text { Normal Ret. }\end{array}$ & $\begin{array}{l}55 \\
55 \\
\end{array}$ & $\begin{array}{l}55 \\
60 \\
\end{array}$ & $\begin{array}{l}55 \\
65 \\
\end{array}$ & $\begin{array}{l}60 \\
60\end{array}$ & $\begin{array}{l}60 \\
65 \\
\end{array}$ & $\begin{array}{l}62 \\
62 \\
\end{array}$ & $\begin{array}{l}62 \\
65 \\
\end{array}$ & 6 \\
\hline No. of Plans & 38 & 63 & 576 & 169 & 86 & 27 & 10 & 5 \\
\hline $\mathrm{Ag \theta}$ & & & & & & & & \\
\hline 50 & .618 & .347 & .209 & .349 & .127 & .017 & .135 & .12 \\
\hline 51 & .106 & .066 & .040 & .065 & .026 & .051 & .021 & .02 \\
\hline 52 & .123 & .082 & .046 & .075 & .029 & .059 & .024 & .03 \\
\hline 53 & .141 & .095 & .052 & .085 & .035 & .068 & .027 & .03 \\
\hline 54 & .160 & .109 & .060 & .098 & .041 & .083 & .030 & .04 \\
\hline 55 & .184 & .125 & .070 & .112 & .047 & .095 & .034 & .05 \\
\hline 56 & .006 & .094 & .069 & .128 & .055 & .101 & .037 & .06 \\
\hline 57 & .002 & .099 & .065 & .146 & .064 & .118 & .042 & .07 \\
\hline 58 & .0003 & .107 & .068 & .167 & .077 & .137 & .047 & .08 \\
\hline 59 & -.004 & .116 & .071 & .185 & .088 & .155 & .053 & .095 \\
\hline 60 & -.010 & .120 & .073 & .209 & .103 & .179 & .056 & .116 \\
\hline 61 & -.016 & .001 & .075 & -.007 & .080 & .198 & .061 & .12 \\
\hline 62 & -.022 & -.004 & .074 & -.015 & .081 & .223 & .067 & .138 \\
\hline 63 & -.029 & -.006 & .075 & -.023 & .080 & -.016 & .035 & .16 \\
\hline 64 & -.036 & -.012 & .075 & -.031 & .083 & -.027 & .034 & .18 \\
\hline 65 & -.043 & -.019 & .073 & -.040 & .084 & -.038 & .032 & .20 \\
\hline 66 & -.116 & -.115 & -.107 &. .192 & -.060 &. .193 & -.077 & -.11 \\
\hline 67 & -.128 & -.137 & -.117 & -.195 & -.074 & -.191 & -.077 & -.126 \\
\hline 68 & -.141 & -.159 & -.125 & -.197 & -.089 & -.190 & -.076 & -.13 \\
\hline 69 & -.154 & -.167 & -.134 & -.197 & -.102 & -.189 & -.075 & -.14 \\
\hline 70 & -.166 & -.174 & -.142 & -.198 & -.114 & -.188 & -.074 & -.148 \\
\hline
\end{tabular}

a. Plans with erly or normal retirement supplements are excluded. 
Table 23. Welghted average accrual rates for percent of earnings plans with 10-year cliff vesting, by early and normal

retirement age, starting job at oge $51 .^{\circ}$

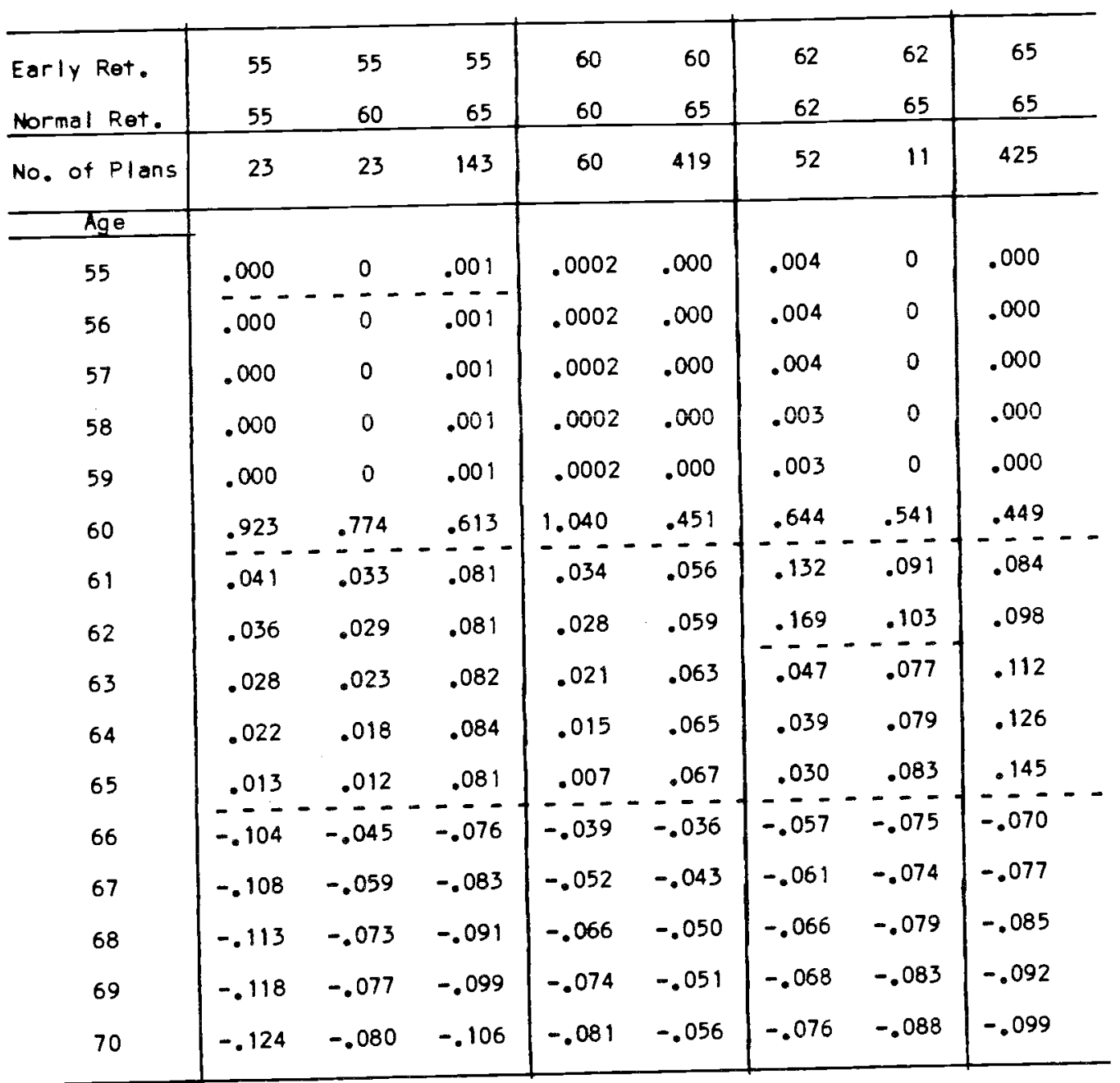

a. Plans with early or normal retirement supplements are excluded. 
Table 24. Pension accrual rates for percent of earnings plans with 10-year clltf vesting, by early and normal retlrement age and by age of Initial employment, for selected ages

\begin{tabular}{|c|c|c|c|c|c|c|c|c|}
\hline \multirow[b]{2}{*}{$\begin{array}{c}\text { Starting Age } \\
\text { and } \\
\text { Age } \\
\end{array}$} & \multicolumn{8}{|c|}{ Early-Normal Ret|rement } \\
\hline & $\begin{array}{l}55 \\
55 \\
\end{array}$ & $\begin{array}{l}55 \\
60 \\
\end{array}$ & $\begin{array}{l}55 \\
65 \\
\end{array}$ & $\begin{array}{l}60 \\
60 \\
\end{array}$ & $\begin{array}{r}60 \\
65 \\
\end{array}$ & $\begin{array}{l}62 \\
62 \\
\end{array}$ & $\begin{array}{r}62 \\
65 \\
\end{array}$ & $\begin{array}{l}65 \\
65 \\
\end{array}$ \\
\hline $31: 40$ & .24 & .11 & .07 & .03 & .05 & .04 & .05 & .04 \\
\hline 50 & .14 & .08 & .05 & .07 & .03 & .07 & .02 & .03 \\
\hline 55 & .26 & .13 & $\Rightarrow 10$ & .15 & .08 & .13 & .04 & .07 \\
\hline 60 & -.0 .04 & .14 & .08 & .27 & .17 & .24 & .05 & .12 \\
\hline 62 & -.06 & -.09 & .06 & -.09 & .12 & .25 & .07 & .15 \\
\hline 65 & -.09 & -.09 & .04 & -.12 & .11 & -.14 & .01 & .21 \\
\hline 66 & -.29 & -.17 & -.15 & -.14 & -.09 & -.27 & -.08 & -.19 \\
\hline $41:{ }_{40}$ & 0 & 0 & 0 & 0 & 0 & 0 & 0 & 0 \\
\hline 50 & 62 & .35 & .21 & .35 & .13 & .02 & .14 & .13 \\
\hline 55 & .18 & .13 & .07 & .11 & .05 & .10 & .03 & .05 \\
\hline 60 & -.01 & .12 & .07 & .21 & .10 & .18 & .06 & .12 \\
\hline 62 & -.02 & -.00 & .07 & -.02 & .08 & .22 & .07 & .14 \\
\hline 65 & -.04 & -.02 & .07 & -.04 & .08 & -.04 & .03 & .20 \\
\hline 66 & -.12 & -.12 & -.11 & -.19 & -.06 & -.19 & -.08 & -.12 \\
\hline $\begin{array}{r}51: \\
40\end{array}$ & 0 & 0 & 0 & 0 & 0 & 0 & 0 & 0 \\
\hline 50 & 0 & 0 & 0 & 0 & 0 & 0 & 0 & 0 \\
\hline 55 & 0 & 0 & 0 & 0 & 0 & 0 & 0 & 0 \\
\hline 60 & .92 & .77 & .61 & 1.04 & .45 & .64 & .54 & .45 \\
\hline 62 & .04 & .03 & .08 & .03 & .06 & .17 & .10 & .10 \\
\hline 65 & .02 & .01 & .08 & .01 & .07 & .03 & .08 & .15 \\
\hline 66 & -.10 & -.05 & -.08 & -.04 & -.04 & -.06 & -.08 & -.07 \\
\hline
\end{tabular}



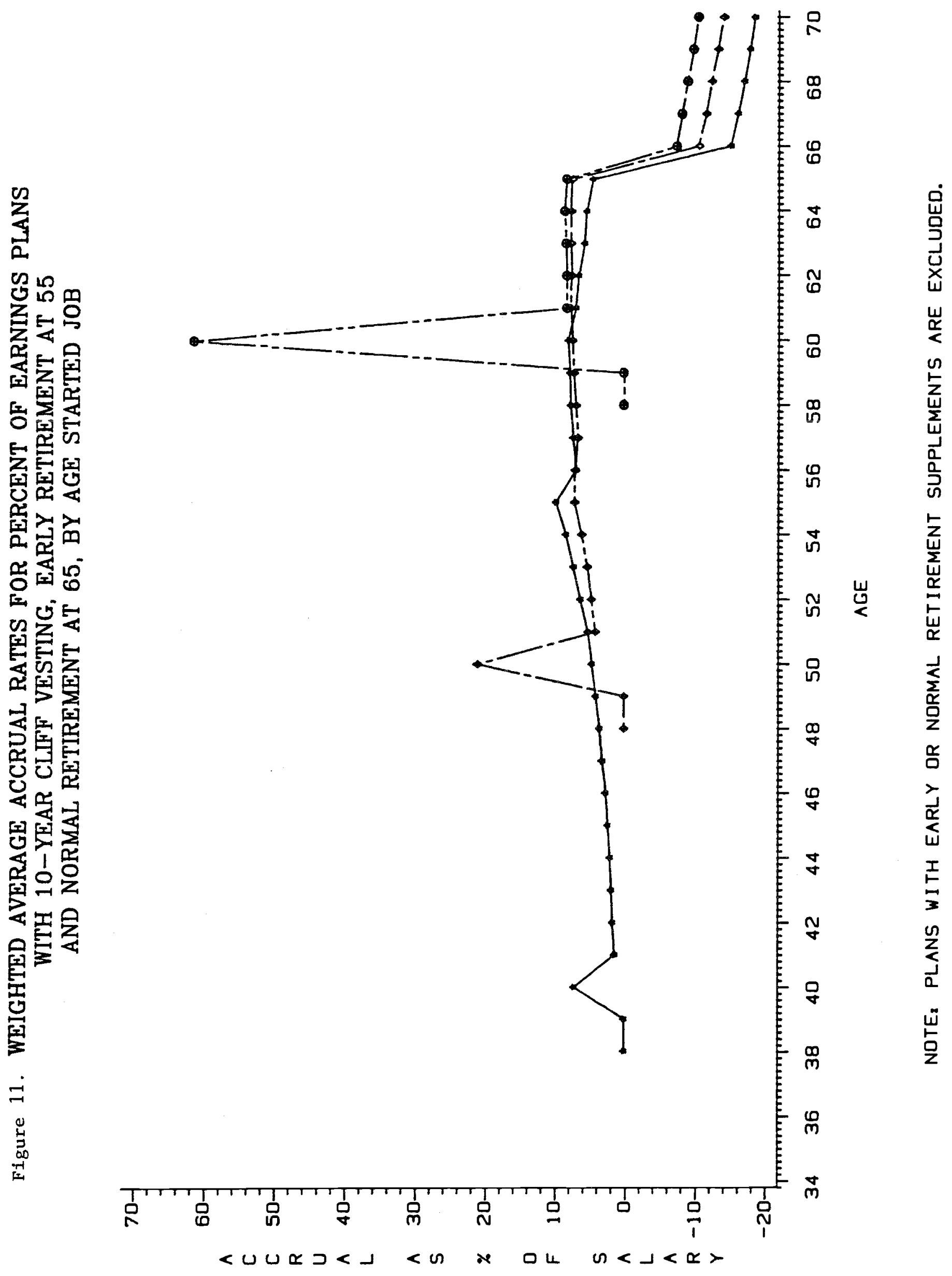
than 65.

\section{Pension Accrual Rates and Pension Cost by Sex}

Because women on average live longer than men, women would typically receive pension benefits longer than otherwise equivalent men. The effect of this difference in life expectancy on pension accrual and the value of pension benefits is considered in this section. The weighted average of the accrued benefits of women versus the accrued benefits of men by age are shown in table 25 for all plans in the sample. At the most common vesting age, 10 years, the ratio is about 1.08 , so that women's vested benefits are approximately 8 percent higher than men's. The ratio increases gradually to abuut 1.10 at age 60 and about 1.13 at 65 . If otherwise identical men and women were to work until age 70, the average ratio would be 1.17 . The ratios do not vary significantly by early and normal retirement age, and thus a breakdown by plan type is not presented.

VI. Summary

The ratios of pension benefit accrual to wage earnings are presented for a wide range of pension plans. Typical plan provisions provide a strong incentive for retirement after the age of plan normal retirement, and several plan types provide a strong incentive for retirement after the age of early retirement. A striking feature of the incentive effects of pension plans is their wide variation among plans. For example, while the average plan may provide reduced but still positive accrual after the age of early retirement, for a large proportion of plans the accrual rate after this age is very negative. Thus it would not be unusual for the reduction in pension benefit 
Table 25. The ratio of accrued pension beneflts of women vs. men, by oge, all plans ${ }^{\circ}$

\begin{tabular}{|c|c|c|c|}
\hline $\mathrm{Age}$ & Ratio & $\mathrm{AgO}$ & Rotio \\
\hline 31 & 1 & 51 & 1.109 \\
\hline 32 & 1 & 52 & 1.106 \\
\hline 33 & 1 & 53 & 1.103 \\
\hline 34 & 1 & 54 & 1.099 \\
\hline 35 & 1.032 & 55 & 1.094 \\
\hline 36 & 1.030 & 56 & 1.096 \\
\hline 37 & 1.032 & 57 & $1=098$ \\
\hline 38 & 1.037 & 58 & 1.101 \\
\hline 39 & 1.036 & 59 & 1.103 \\
\hline 40 & 1.082 & 60 & 1.102 \\
\hline 41 & 1.083 & 61 & 1.108 \\
\hline 42 & 1.085 & 62 & 1.113 \\
\hline 43 & 1.087 & 63 & 1.120 \\
\hline 44 & 1.089 & 64 & 1.126 \\
\hline 45 & 1.091 & 65 & 1.131 \\
\hline 46 & 1.094 & 66 & 1.138 \\
\hline 47 & 1.096 & 67 & 1.145 \\
\hline 48 & 1.099 & 68 & 1.153 \\
\hline 49 & 1.102 & 69 & 1.161 \\
\hline 50 & 1.105 & 70 & 1.170 \\
\hline
\end{tabular}

a. There are 2342 plans. Starting age is 31 . 
accrual after the age of early retirement to be equivalent to a 30 percent reduction in wage earnings. The accrual rate at the age of vesting can range from as low as 2 percent of wage earnings in that year to as high as 100 percent of wage earnings, depending upon the plan type and on the age of initial employment. Thus for some employees, vesting could be a very important determinant of labor force participation decisions. Special early and normal retirement provisions may also add very substantially to accrued pension wealth at particular ages and may thus encourage workers to remain with a firm until these benefits are received. The accrual profiles under flat benefit plans seem very similar to the accruals under percent of earnings plans, if one assumes that the flat benefit is increased to keep pace with the rate of inflation. Given early and normal retirement ages, there is little difference in plan accrual profiles by industry or by occupation. Differences in pension benefits by industry depend more on the type of plan than on variations among plans with the same basic provisions. While the expected loss in pension benefits due to job change is apparently relatively small in many instances, it is rather large in others, and there is very wide variation among plans with the loss very high in some cases and, indeed, in other cases a gain may be had by changing job. In addition, accrued benefits at the age of retirement are typically very mich lower with job change than if a person remains on the same job. Because women typically live longer than men, accrued pension benefits at any age are higher for women than for men, about 13 percent on average at age 65 , for example. In short, the evidence suggests that the rapid increase in pension plan coverage over the past two or three decades may well have contributed very substantially to the reduction in the labor force participation of older workers during this period. The plans may also have an important effect on labor mobility. 


\section{FOOTNOTES}

1. Gary Heaton accomplished the very substantial programing task that the paper required and served as a continuous source of information, explanation, and expertise. We thank Tom Gustafson for his very helpful comments.

2. Only plans with incomplete or inconsistent information were classified by the BLS as unusable.

3. Our calculations ignore service requirements for early retirement, since this inclusion could have considerably complicated our accrual computations. Excluding early retirement service requirements from the analysis is not likely to significantly alter the results. Virtually all workers covered by such requirements are enrolled in plans with early retirement service requirements of 15 years or less. (Kotlikoff and Smith, 1983). 


\section{References}

Bulow, J. 1979. "Analysis of pension funding under ERISA". NBER Working Paper no. 402.

Kotlikoff, Laurence J. and Smith, Daniel. 1983. Pensions in the American Economy, Chicago University Press, Chicago, Illinois.

Kotlikoff, Laurence J. and Wise, David A. 1984. "Labor Compensation and the Structure of Private Pensions Plans: Evidence for Contractual Versus Spot Labor Markets," National Bureau of Economic Research Working Paper No. 1290.

Lazear, E. P. 1983. Pensions as severance pay. Chapter three in "Financial Aspects of the United States Pension System", Zvi Bodie and John B. Shoven eds., Chicago: University of Chicago Press.

Lazear, E. P. 1981. Severance pay, pensions, mobility, and the efficiency of work incentives. Mimeo, University of Chicago. 


\section{APPENDIX}

The source of discontinuities in age accrual profiles is clarified by considering a simple earnings-related defined benefit plan with "cliff vesting" at 10 years of service. Vested accrued benefits are clearly zero prior to the age at which the worker has ten years of credited service in the plan. Iuet $R(a, t)$ denote the ratio of $I(a)$ to $w(a)$ for a worker age a with $t$ years of tenure, where $I(a)$ is defined in $(1)$ in the text. Then $R(a, t)$ is zero for $t \leqslant 9$. If a person age a with 9 years of service works an additional year, the ratio of the increment to the wage, $W(a)$, is

$$
R(a, 9)=\frac{B(a, t) A(55)(1+d)^{10}(1+r)^{(55-(a+1))}}{W(a)}
$$

In $(A 1), B(a, t)$ is the retirement benefit available to the worker who terminates employment with the plan sponsor at age a after $t$ years of service, but who delays receipt of pension benefits until the plan's normal retirement age. The normal and early retirement ages assumed for this stylized plan are 65 and 55 respectively. Terminating workers in this example are eligible for early retirement benefits. Our hypothetical plan reduces benefits by d percent for each year that early retirement preceeds normal retirement. The benefit reduction rate, $d$ is assumed to be less than the actuarial fair rate. The function $\mathrm{A}(55)$ is the actuarial discount factor that transforms benefit flows initiating at age 55 into expected stocks of pension wealth at age 55. Expectations here are taken with respect to longevity. Thus $A(55)$ is the annuity value of a dollar's worth of pension benefits to be received each year until death, beginning at age 55. For simplicity asume that the probability of dying prior to age 55 is zero. Hence the present value at age a of $\mathrm{A}(55)$ is 
$A(a)=A(55)(1+r)^{-(55-a)}$ for $a \leqslant 55$. If pension benefits are determined as a constant $\lambda$ times the product of final year's earnings and service, and there is no offset for receipt of social security benefits, $B(a, t)$ is simply:

(A2) $\quad B(a, t)=\lambda W(a) t$, and

$$
\begin{aligned}
& \mathrm{R}(\mathrm{a}, 9)=\lambda(1+\mathrm{d})^{-10}(1+r)^{-(55-(a+1))} \mathrm{A}(55) 10 \frac{W(a+1)}{W(a)} . \\
& P(a, t) \text {, for } t \text { increasing pari-passus with age, is zero prior to } t
\end{aligned}
$$

equals 9 and jumps at $t$ equals 9 to the value given in (A3). Cliff vesting thus produces spikes in the accrual profile such as that in Figure 1 at 10 years of service. Between the age at cliff vesting and age 55 pension wealth, Pw(a), is given by:

$$
P_{W}(a)=\lambda W(a)(1+d)^{-10}(1+r)^{-(55-a)} A(55) t,
$$

and the increment to pension wealth $I(a)$ divided by the wage $W(a)$ is given by

$$
\text { (A5) } \quad R(a, t)=\lambda(1+d)^{-10}(1+r)^{-(55-(a+1))} A(55) t\left[\frac{W(a+1)}{W(a)} \frac{t+1}{t}-1\right]
$$

Equations (A3) and (A5) suggest a drop in $R(a, t)$ as a increases to $a+1$ concurrent with an increase in trom 9 to 10. Equation (A5) will be positive if the bracketed term exceeds zero. This will be the case if the percentage increase in the wage plus the percentage increase in years employed $(1 / t)$ is greater than zero. Assuming the term in brackets is positive and is roughly constant, $R(a, t)$ will increase exponentially due to the exponential decline in the discount factor, $(1+r)^{-(55-(a+1))}$, as a approaches 55 .

If the value of $d$ is considerably less than actuarially fair, a discontinuity in $R(a, t)$ occurs at the early retirement age, 55 . At ages 55 and 56 we have: 
(A6) $\quad \operatorname{PW}(55)=\lambda \mathrm{W}(55)(1+d)^{-10} \mathrm{~A}(55) t$, and

(A7) $\quad \mathrm{PW}_{\mathrm{W}}(56)=\lambda \mathrm{W}(56)(1+\mathrm{d})^{-9} \mathrm{~A}(56)(t+1)$.

Hence,

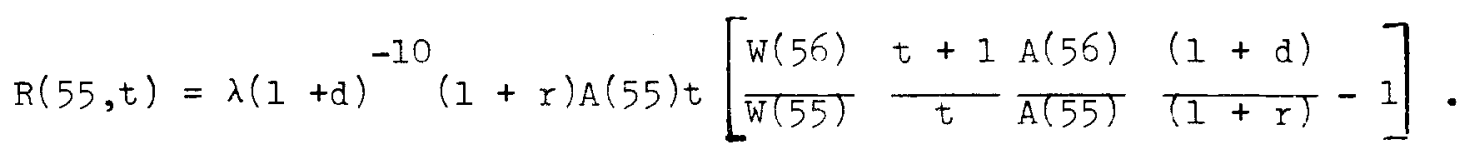

Assuming wage growth at 54 is close to that at 55 and $A(56)$ approximately equals $A(55)$, then $R(55, t)$ primarily differs from $R(54, t-1)$ because the first terms in the bracket in (7) is now maltiplied by $(1+d)$ while the second term, -1 , is miltiplied by $(1+r)$. Since $r$ exceeds $d$ by assumption, $R(55, t)$ can easily be less than $R(54, t-1)$. Indeed, this change in the functional form of $R(a, t)$ can produce sharp drops in accrual rates at the early retirement age for a host of pension plans and a range of realistic economic as sumptions.

It is important to realize that the early retirement reduction, lower wages, and one less year of tenure yield lower benefits at 55 than at 56 . The early retirement reduction reduces benefits at the rate d. But if benefits were taken at 55 they could accrue interest at the rate $r$. Thus by foregoing the early retirement option of receiving benefits at 55, a cost is incurred that depends on the difference $r-d$. If this loss is not offset by the increase due to wage growth and 1 year of additional tenure, there will be a drop in the benefit accrual rate between 55 and 56.

The same considerations pertain to benefit increments between 56 and 65. Recall that we have assumed a less than fair early retirement reduction 
so that benefits accrued before 55 are valued based on the assumption that benefits are received starting at the age that yields maximum pension wealth. The optimum time to receive benefits accrued between 55 and 56 is 56 , between 56 and 57 is 57 , and so forth. But to gain benefits from working another year, it is necessary to forego the option of immediately taking acrued benefits at an advantageous reduction rate.

Between ages 56 and $65, R(a, t)$ equals:

(A9) $\quad R(a, t)+\lambda(1+d)^{-(65-a)}(1+r) A(a) t\left[\frac{W(a+1)}{W(a)} \frac{(t+1)}{t} \frac{A(a+1)}{A(a)} \frac{(1+d)}{(1+r)}-\right.$ In contrast to the $R(a, t)$ formula in (A5) that applies to the period between cliff vesting and early retirement, $(A O)$ indicates that the actuarial reduction factor $d$, rather than the interest rate $r$, imparts an upward tilt in the $R(a, t)$ profile between early and normal retirement, as long as the term in brackets is positive. In (A9) as in (A5) and (A8) the accrual rate, $R(a, t)$, is an increasing function of the rate of nominal wage growth. Larger nominal interest rates reduce acrual rates at all ages, with a negative interaction with age prior to early retirement.

While the expression (A5) is unlikely to be negative, large differences between wage growth and the interest rate $r$ can yield negative increments in pension wealth after the early retirement age. To a first approximation, the bracketed term in equation (A9) will be positive if $\Delta W / W+I / t>r-d$, where $\Delta W / W$ is the percentage increase in wages, and $I / t$ is the percentage increase in tenure. It is easy to see, however, that low wage growth and high interest rates will yield negative increments. 
Pension accrual after normal retirement can be significantly negative. Assume that our hypothetical plan neither credits service after normal retirement nor provides an actuarial increase in benefits for postponing benefit receipt beyond the normal retirement age. In this case $R(a, t)$ after normal retirement is given by: (A10) $\quad R(a, t)=\lambda t * A(a) \quad\left[\frac{A(a+1)}{A(a)}-(1+r)\right]$, Where $t^{*}$ equals the worker's service prior to age 65. Note that for the following reasonable parameter values:

$$
\lambda=.02, t^{*}=30, \mathrm{~A}(\mathrm{a})=15, \mathrm{r}=.04 \text {, and } \mathrm{A}(\mathrm{a}+1)=14, \mathrm{R}(\mathrm{a}, \mathrm{t})=-.96 \text {, }
$$

a quite substantial negative accrual ratio.

While the preceeding formulae are suggestive of the general shape of accrual rate profiles, there are few earnings-based plans with features as simple as the one considered here. In addition to more complicated rules for plan participation and vesting that often involve age as well as service requirements, there are a variety of methods of computing earnings bases, including career averages, and averages of earnings, possibly highest earnings, over a specified period or number of years. Reduction rates for early retirement are often a specified function of age, if not length of service. Some plans allow no further accrual after a given number of years of service. Roughly thirty percent of defined benefit participants belong to plans that are integrated with social security, and the form of "integration" can have an important effect on the pattern of benefit accrual. Other plans, in particular, those with social security offset formulae, provide supplemental benefits for early retirees prior to their receipt of social security benefits. In addition to these earnings-related plans, a significant number of plans 
covering over forty percent of defined benefit participants calculate benefits independent of the participant's earnings. Finally, there are plans that specify minimun and maximum benefit levels. 